\title{
El administrador de recursos humanos como gestor del talento humano Sus competencias y la relación con las prácticas de administración de recursos humanos ${ }^{1}$
}

\author{
Ma. del Carmen Liquidano Rodríguez*
}

\begin{abstract}
Resumen
El objetivo general de este estudio fue identificar si el actual administrador de recursos humanos es un gestor del talento; asimismo, identificar las competencias y rasgos personales de su perfi, así como conocer si existe relación entre sus competencias cognitivas, conductuales y técnicas, y rasgos personales predominantes con las prácticas que aplica de la administración de recursos humanos; para llevar a cabo lo anterior, se analizan 28 prácticas. Este trabajo aporta al conocimiento la identificación de una mayor correlación significativa entre nueve competencias técnicas y ocho competencias cognitivas del perfil del administrador de recursos humanos, así como la identificación de empresas en sus formas de administrar y en sus prácticas de administración de recursos humanos desde la fase administrativa, de gestión, de desarrollo, estratégica, por competencias hasta la gestión del conocimiento del talento humano, aunque esta última en forma muy incipiente. En los hallazgos que se encontraron se identifica el gestor administrativo, el gestor de recursos humanos y sólo en sus formas de concebir al hombre y de percibir al personal se observa como gestor del talento humano. El estudio se realizó con un análisis descriptivo y correlacional que se aplicó a 219 ejecutivos o personas que realizan la función de recursos humanos en empresas de Aguascalientes.
\end{abstract}

Palabras clave: gestor del talento, competencias del administrador de recursos humanos y prácticas de administración de recursos humanos.

\footnotetext{
${ }^{1}$ Basado en la investigación que para obtener el grado de Doctor en Administración realizó la autora con el título: "El impacto del perfil del administrador de RH en la evolución de la gestión de recursos humanos y su relación con el desempeño organizacional en empresas de Aguascalientes".

* Profesora investigadora y presidenta del Consejo de Posgrado en Administración del Instituto Tecnológico de Aguascalientes. Correo electrónico: mcliquidano@yahoo.com.mx
} 


\section{Introducción}

En años recientes, en los ámbitos empresarial y académico se ha analizado el área de administración de recursos humanos debido a la importancia de sus funciones para atraer y retener al talento humano de la empresa como clave para la generación de ventajas competitivas en los negocios, a través del incremento y mejora de las prácticas de recursos humanos. Autores como García Pineda y Hernández Sánchez (2000) plantean que los esquemas de análisis de competitividad de las empresas como de mejora continua y control estadístico de procesos resultaron al final de los años noventa sólo herramientas que podían ser imitadas, copiadas y hasta mejoradas por el competidor más cercano o el más astuto; por ello, surge la gestión del conocimiento como una fuerza que determina la competitividad y productividad de las empresas.

Debido a lo anterior, el objetivo general de este estudio fue identificar si el actual administrador de recursos humanos es un gestor del talento; asimismo, identificar las competencias y rasgos personales de su perfil y conocer si existe relación entre sus competencias cognitivas, conductuales y técnicas, así como los rasgos personales predominantes con las prácticas que aplica de la administración de recursos humanos $(\mathrm{RH})$ para lo cual se analizaron 28 prácticas.

En la estructura de este trabajo se presenta un análisis breve del marco conceptual de la gestión del conocimiento del talento humano, las competencias y rasgos personales del perfil del administrador y las prácticas de administración de recursos humanos. De igual forma, se plantea el problema incluyendo los objetivos, preguntas de investigación, hipótesis y justificación. También se incluye el diseño metodológico, cobertura de la muestra, la operacionalización y medición de las variables, la validez de los instrumentos y los resultados que se obtuvieron de donde se extraen las principales conclusiones del estudio.

\section{Antecedentes e importancia de la administración de recursos humanos como gestión del conocimiento}

La denominación de gestión del talento humano o gestión del conocimiento del talento humano se empezó a emplear en años recientes por los autores Chiavenato (2002), García y Hernández (2000), Salleh \& Wee - Keat (2002), entre otros. 
El administrador de recursos humanos como gestor del talento humano...

Cuando se habla de gestión del conocimiento del talento humano, se hace referencia a las funciones y actividades que realiza el área que hasta el momento es conocida y reconocida por los administradores de recursos humanos, lo cual observamos al administrar el personal en la empresa y se relaciona con el área, sus funciones o roles, así como al responsable de llevarlas a cabo; de este último, deriva la denominación de gestor del talento humano o gestor del conocimiento del talento humano.

Sin embargo, este tipo de administración ha evolucionado. Losey (1998) al analizar la historia de la administración de recursos humanos identifica y la denomina como "movimientos de la administración de personal (1800 a 1935) de las relaciones humanas (1920 a 1947) y de los recursos humanos (segunda mitad de la centuria a 1998)"; por su parte Plane (2003) señala además los "movimientos del desarrollo del potencial humano (a mitad de la década de los noventa) y de la gestión de la competitividad y del empleo" (hasta nuestros días).

En la evolución de la gestión de recursos humanos han influido diversas causas y factores (Valle, 1995): una de esas causas es la concepción de "hombre" que ha tenido la humanidad; uno de los factores ha sido los movimientos de evolución de la gestión, como aportación de este estudio, estas causas y factores permiten identificar seis fases de evolución de la gestión de recursos humanos: administrativa, de gestión, de desarrollo, estratégica, gestión por competencias y gestión del conocimiento (Liquidano, 2005). Con base en los movimientos históricos de evolución, se argumenta que las fases no tienen un inicio ni una conclusión determinante, sino que se siguen manifestando aunque en menor cantidad en las prácticas de administración de RH, pues se parte del supuesto de que actualmente en las empresas se pueden presentar las seis fases de gestión. A continuación se presenta la definición de cada una de las fases de evolución de la gestión de recursos humanos, así como la identificación del tipo de gestor o administrador que realiza predominantemente esa forma particular de administrar (ver tabla 1). 
Tabla 1

\section{Definición de las fases de evolución de la gestión de recursos humanos e identificación del tipo de gestor o administrador}

\begin{tabular}{|c|c|c|}
\hline $\begin{array}{c}\text { Fase de } \\
\text { evolución }\end{array}$ & $\begin{array}{c}\text { Definición de cada una de las fases con base en sus principales formas de } \\
\text { administrar los recursos humanos }\end{array}$ & $\begin{array}{l}\text { Tipo de gestor } 0 \\
\text { administrador }\end{array}$ \\
\hline Administrativa & $\begin{array}{l}\text { Administración del personal en una organización donde el administrador } \\
\text { concibe al individuo como un ser racional y económico; dirige al personal de } \\
\text { la empresa hacia la producción; valora o percibe al personal como un costo } \\
\text { que se requiere minimizar; su relación laboral es a través de controles de } \\
\text { recompensas y castigos; además, las prácticas que realiza son } \\
\text { predominantemente: reclutamiento, selección, contratación y despido, } \\
\text { adiestramiento, administración de sueldos y salarios, relaciones laborales, } \\
\text { registros y controles administrativos. }\end{array}$ & Gestor administrativo \\
\hline Gestión & $\begin{array}{l}\text { Administración del personal en una organización donde el administrador } \\
\text { concibe al individuo como ser social; dirige al personal hacia la satisfacción } \\
\text { de sus necesidades sociales y psicológicas; valora o percibe al personal como } \\
\text { un costo a minimizar, pero con acciones de carácter proactivo (con iniciativa, } \\
\text { responsables de su vida) con una relación laboral hacia los factores } \\
\text { retributivos y psicológicos y las prácticas que realiza, además de las } \\
\text { anteriores, son predominantemente: capacitación y desarrollo, formación de } \\
\text { personal, administración de sueldos y salarios, análisis y descripción de } \\
\text { puestos, relaciones laborales y negociaciones colectivas, registros y controles } \\
\text { administrativos, gráficas y estadísticas, motivación y comunicación, auditoría } \\
\text { laboral, uso de computadora como herramienta de control y sólo principios y } \\
\text { valores personales. }\end{array}$ & $\begin{array}{l}\text { Gestor o administrador de } \\
\text { personal }\end{array}$ \\
\hline Desarrollo & $\begin{array}{l}\text { Administración de recursos humanos en una organización donde el } \\
\text { administrador concibe al individuo como personas que se auto-realizan; } \\
\text { dirige al personal hacia la eficiencia de la empresa; valora al personal como } \\
\text { el elemento determinante para el desarrollo de la empresa y un recurso a } \\
\text { optimizar con relaciones laborales a través de la motivación y estímulos al } \\
\text { rendimiento; asimismo, las prácticas que realiza además de las anteriores son } \\
\text { predominantemente: planeación de vida y carrera, criterios de promoción, } \\
\text { higiene y seguridad, evaluación del desempeño, planeación de recursos } \\
\text { humanos, índices de rotación y ausentismo, responsabilidad social. }\end{array}$ & $\begin{array}{l}\text { Gestor o administrador de } \\
\text { recursos humanos }\end{array}$ \\
\hline Estratégica & $\begin{array}{l}\text { Administración estratégica de recursos humanos en una organización donde } \\
\text { el administrador concibe al individuo como personas dinámicas y capaces de } \\
\text { evolucionar a través de nuevos conocimientos y experiencias pasadas; dirige } \\
\text { al personal hacia la estrategia del negocio, lo valora y percibe como un } \\
\text { recurso a optimizar y factor determinante para la mejora de la posición } \\
\text { competitiva de la empresa, con relaciones laborales hacia el cumplimiento de } \\
\text { los objetivos con base en la estrategia del negocio; asimismo, las prácticas } \\
\text { que realiza, además de las anteriores, son predominantemente: procedimiento } \\
\text { de quejas, planeación estratégica de recursos humanos, controles } \\
\text { estratégicos, administración internacional de RH y programas de calidad. }\end{array}$ & $\begin{array}{l}\text { Gestor estratégico } \\
\text { recursos humanos }\end{array}$ \\
\hline
\end{tabular}


El administrador de recursos humanos como gestor del talento humano...

\begin{tabular}{|c|c|c|}
\hline Fase de evolución & $\begin{array}{l}\text { Definición de cada una de las fases con base en sus } \\
\text { principales formas de administrar los recursos } \\
\text { humanos }\end{array}$ & $\begin{array}{l}\text { Tipo de gestor o } \\
\text { administrador }\end{array}$ \\
\hline Por competencias & $\begin{array}{l}\text { Administración por competencias del capital humano } \\
\text { en una organización donde el administrador concibe al } \\
\text { individuo como personas que poseen características } \\
\text { de desempeño superior; dirige al personal hacia la } \\
\text { identificación, descripción y desarrollo de } \\
\text { competencias individuales para impulsar el nivel de } \\
\text { excelencia hacia los resultados; valora y percibe al } \\
\text { personal como el que da mantenimiento a la ventaja } \\
\text { competitiva de la empresa por las competencias que } \\
\text { posee con relaciones laborales hacia el desarrollo, } \\
\text { evaluación y certificación de las competencias en el } \\
\text { trabajo y para el trabajo; además, realiza } \\
\text { predominantemente las } 28 \text { prácticas, pero su enfoque } \\
\text { es hacia el desarrollo, evaluación y certificación de } \\
\text { competencias para mantener la ventaja competitiva e } \\
\text { incrementar la productividad. }\end{array}$ & $\begin{array}{l}\text { Gestor por competencias del } \\
\text { capital humano }\end{array}$ \\
\hline Del conocimiento & $\begin{array}{l}\text { Administración del conocimiento del talento humano } \\
\text { en una organización donde el administrador concibe al } \\
\text { individuo como el talento clave para la empresa; dirige } \\
\text { al personal hacia el aprendizaje, retención y } \\
\text { motivación del conocimiento del personal; percibe y } \\
\text { valora al personal en cuanto a su talento y } \\
\text { conocimiento; integra el capital humano y social de la } \\
\text { empresa con relaciones laborales adoptando las } \\
\text { mejores prácticas de la ARH para retener y motivar el } \\
\text { conocimiento de los trabajadores, por lo que realiza } \\
\text { predominantemente las } 28 \text { prácticas hacia el enfoque } \\
\text { mencionado. }\end{array}$ & $\begin{array}{l}\text { Gestor del conocimiento del } \\
\text { talento humano }\end{array}$ \\
\hline
\end{tabular}

Nota: se abreviaron las prácticas sólo mencionando las que se van incluyendo en la medida en que evoluciona la gestión de recursos humanos. Los criterios definidos para identificar las variables fueron: concepción del hombre, orientación del personal, percepción o valoración del personal, relaciones laborales y prácticas de administración de recursos humanos que aplican (Liquidano, 2005). La continuación de la tabla 1 es aportación de la autora

\subsection{Competencias y rasgos personales del perfil del administrador de recursos humanos $(\mathbf{R H})$}

Se ha estudiado el perfil del administrador con relación a las características demográficas: nivel y tipo de educación, experiencia en número de años en el negocio y ocupación previa; los resultados muestran que las empresas con alta perspectiva de crecimiento fueron administradas por personas con un alto nivel educativo 
(Wasilczuk, 2000); sin embargo, el perfil no sólo se conforma con sus características demográficas, también es necesario conocer las competencias que lo integran en virtud de que se detecta la necesidad de un nuevo perfil del administrador de RH hacia la integración de gerentes con competencias globales (Adler \& Bartholomew, 1992); asimismo, que puedan tener las capacidades para ser las soluciones y tengan una orientación hacia la visión de negocios que permita atraer, retener y medir la competencia y el capital intelectual del personal (Lugo, 1999) con una visión holística de la organización, capaces de definir metas estratégicas, cooperativos con los empleados, familiarizados en las finalidades del negocio; Lugo plantea que las habilidades y competencias requeridas a los gerentes de recursos humanos son: administración del cambio, el trabajo en equipo, las herramientas clásicas de administración de RH, administración general, consultoría y comunicación, negocios, administración internacional y multicultural, conceptos y teorías de ARH, entre otros aspectos.

Además, en años recientes, varios autores han realizado estudios teóricos sobre la clasificación y descripción de las competencias que puede tener el dueño, gerente y el gestor de recursos humanos, como es el caso de Valle (1995), que identifica como perfil profesional; por su parte Alles (2000) integra varios tipos de competencias: técnicas, las derivadas de la gestión, las mentales o cognitivas, las universales para cuadros superiores y las competencias clave de éxito, así, una de las propuestas del estudio fue la integración del perfil del administrador de $\mathrm{RH}$, con las dimensiones: competencias cognitivas, conductuales, técnicas y rasgos personales, además de las características demográficas. Para realizar esta propuesta se retoman principalmente los criterios de Alles (2000), así como de Lugo (1999), quien la integra como constructo de la variable "perfil del administrador o gestor de $R H^{\prime \prime}$, lo cual se detalla en la tabla 2. 
El administrador de recursos humanos como gestor del talento humano...

Tabla 2

Constructo de la variable perfil del administrador de RH y sus dimensiones: competencias cognitivas, conductuales, técnicas, rasgos personales y características demográficas

\begin{tabular}{|c|c|c|c|c|}
\hline $\begin{array}{l}\text { Características } \\
\text { demográficas }\end{array}$ & Competencias cognitivas & $\begin{array}{l}\text { Competencias } \\
\text { conductuales }\end{array}$ & $\begin{array}{c}\text { Competencias } \\
\text { técnicas }\end{array}$ & Rasgos personales \\
\hline * Género & *Pensamiento analítico. & * Iniciativa & $\begin{array}{l}\text { *Administrador y visión de } \\
\text { cambio }\end{array}$ & *Flexibilidad \\
\hline * Edad del ARH & *Capacidad de aprender & $\begin{array}{l}\text { *Orientación hacia la } \\
\text { satisfacción del cliente }\end{array}$ & *Habilidades para los negocios & *Se adapta \\
\hline * Escolaridad & *Pensamiento crítico & $\begin{array}{l}\text { * Planeación de funciones a } \\
\text { mediano y largo plazos }\end{array}$ & $\begin{array}{l}\text { *Conocimiento de leyes } \\
\text { laborales }\end{array}$ & $\begin{array}{l}\text { *Toma buenas } \\
\text { decisiones }\end{array}$ \\
\hline *Ocupación previa & $\begin{array}{l}\text { *Habilidades para solucionar } \\
\text { problemas. }\end{array}$ & $\begin{array}{l}\text { *Comunicación hacia el } \\
\text { personal }\end{array}$ & *Conocimiento de informática & *Dinámico \\
\hline * Puesto & *Habilidades directivas & *Habilidades interpersonales & *Conocimiento del inglés & *Visionario \\
\hline $\begin{array}{l}\text { * Antigüedad en la } \\
\text { empresa. }\end{array}$ & $\begin{array}{l}\text { *Conocimiento de la cultura } \\
\text { organizacional }\end{array}$ & *Trabajo en equipo & $\begin{array}{l}\text { *Conocimiento de } \\
\text { administración general }\end{array}$ & *Tiene autoconfianza \\
\hline \multirow[t]{8}{*}{$\begin{array}{l}\text { * Antigüedad en el } \\
\text { pueso. }\end{array}$} & $\begin{array}{l}\text { *Uso de información y análisis de } \\
\text { datos }\end{array}$ & $\begin{array}{l}\text { *Ambiente de entusiasmo y } \\
\text { compromiso }\end{array}$ & $\begin{array}{l}\text { *Habilidades técnicas y } \\
\text { estratégicas de su área }\end{array}$ & *Competente \\
\hline & $\begin{array}{l}\text { *Creador de entornos de } \\
\text { sociabilidad }\end{array}$ & $\begin{array}{l}\text { *Líder - guía de compañeros y } \\
\text { subordinados }\end{array}$ & -Actualización & *Valores humanos \\
\hline & $\begin{array}{l}\text { *Conocimiento de la estrategia del } \\
\text { negocio }\end{array}$ & *Motivación al personal & $\begin{array}{l}\text { *Habilidades para reaccionar y } \\
\text { adaptarse a los cambios. }\end{array}$ & *Paciente \\
\hline & $\begin{array}{l}\text { *Habilidades de organización de } \\
\text { eventos y procesos de intercambio } \\
\text { de conocimientos. }\end{array}$ & *Delegando & $\begin{array}{l}\text { *Involucramiento de la función } \\
\text { de ARH a la estrategia del } \\
\text { negocio. }\end{array}$ & $\begin{array}{l}\text { *Preciso y firme en } \\
\text { sus decisiones. }\end{array}$ \\
\hline & & $*$ Cooperando & $\begin{array}{l}\text { *Conocimiento de } \\
\text { administración internacional y } \\
\text { varias culturas. }\end{array}$ & \\
\hline & & *Tolerante & & \\
\hline & & $\begin{array}{l}\text { *Recompensando el } \\
\text { desempeño }\end{array}$ & & \\
\hline & & *Alto grado de realización & & \\
\hline
\end{tabular}

Fuente: Aportación de la autora 
Sin embargo, para este estudio, sólo se incluyeron las competencias y los rasgos del perfil del administrador de RH.

\subsection{Prácticas de administración de recursos humanos}

En relación con las prácticas de la administración de recursos humanos (PARH) se puede afirmar que han variado con el tiempo, cada vez se han tornado más complejas y sofisticadas en su aplicación; es decir, han evolucionado y se fundamentan en el avance que ha tenido la gestión de recursos humanos (EGRH). En este estudio se argumenta que las funciones o PARH permiten identificar la fase de gestión predominante como administrativa, de gestión, de desarrollo, estratégica, por competencias y gestión del conocimiento. Entre los estudios empíricos que han analizado el perfil del administrador de RH y su relación con las prácticas de administración se puede mencionar a Sirianni (1992), quien reconoce la necesidad de orientar la administración de recursos humanos hacia una visión más estratégica, tanto en las grandes y pequeñas empresas italianas; de igual forma afirma que se debe incrementar el nivel de formalización de la función de personal, grado de sofisticación y uso de prácticas, de técnicas y metodologías de la ARH; también que debe existir un rol estratégico de recursos humanos y un relativo involucramiento de la función del personal; destaca que los procesos de administración deben ser determinados de acuerdo con las características del personal de la empresa (cultura, educación y habilidades, entre otros aspectos). Welbourne \& CYR (1999) exploraron el efecto de contar con un ejecutivo superior en el área de RH en compañías emprendedoras orientadas al crecimiento.

\section{Planteamiento del problema}

Por lo anterior, se puede afirmar que la administración de recursos humanos ha pasado por varias fases de evolución; para Liquidano (2005) existen seis fases: administrativa, gestión, desarrollo, estratégica, por competencias y gestión del conocimiento; sin embargo, se requiere conocer si el administrador de recursos humanos es actualmente un gestor del conocimiento del talento humano, si sus prácticas y sus formas predominantes de administrar lo ubican en otro tipo de gestión, ¿qué rasgos personales y competencias predominan en él?, ¿existe relación entre las competencias del gestor de RH y las prácticas de su función? 
El administrador de recursos humanos como gestor del talento humano...

\subsection{Objetivos y preguntas de investigación}

El objetivo general de este estudio fue identificar si el actual administrador de recursos humanos es un gestor del talento; identificar las competencias y rasgos personales de su perfil; asimismo, conocer si existe relación entre sus competencias cognitivas, conductuales y técnicas con sus rasgos personales predominantes en las prácticas que aplica de la administración de $\mathrm{RH}$, para ello se analizaron 28 prácticas.

Los objetivos específicos que se pretenden alcanzar son los siguientes:

- Identificar si el administrador de recursos humanos es un gestor del talento a través de sus principales formas de administrar, así como por las prácticas que aplica al personal de su empresa.

- Describir las competencias y rasgos personales del administrador de RH.

- Identificar la relación entre las competencias y rasgos del administrador de recursos humanos con las prácticas de gestión de RH en empresas de Aguascalientes $^{2}$

En consecuencia, se tratarán responder las preguntas: ¿cuáles son las competencias y rasgos personales del perfil del administrador que está dirigiendo las empresas?, ¿el administrador actual es un gestor del talento humano?, ¿cuál es la relación de las competencias del perfil del administrador de $\mathrm{RH}$ con las prácticas de la administración de RH?, ¿el administrador de RH está realizando prácticas de administración o gestión del conocimiento?, ¿está realizando prácticas en otras fases de evolución?

\subsection{Hipótesis de estudio}

Con base en el planteamiento del problema, los objetivos y preguntas de investigación la hipótesis de este estudio es:

\footnotetext{
${ }^{2}$ Basado en la investigación que para obtener el grado de Doctor en Administración realizó la autora con el título: "El impacto del perfil del administrador de RH en la evolución de la gestión de recursos humanos y su relación con el desempeño organizacional en empresas de Aguascalientes."
} 
H1: Existe una relación estadísticamente significativa entre las competencias cognitivas, conductuales, técnicas y los rasgos personales del perfil del administrador de recursos humanos $(R H)$ con sus prácticas de administración de $R H$.

Planteando como Ho: No existe una relación estadísticamente significativa entre las competencias cognitivas, conductuales y los rasgos personales del perfil del administrador de recursos humanos $(R H)$ con sus prácticas de administración de $R H$.

\subsection{Justificación}

Este trabajo se planteó con la finalidad de analizar todas las fases de gestión de recursos humanos a la vez; asimismo, se identifican las que predominan en las empresas de Aguascalientes; de igual manera, se trata de aportar al conocimiento de los recursos humanos que los rasgos y competencias de los individuos que administran al personal tienen relación con las prácticas que realizan. También se pretende que las aportaciones del estudio generen una reflexión en el lector sobre su forma de gestión actual, así como los desafíos que se le presentan para ser un gestor del talento humano; finalmente, se identificarán las necesidades de capacitación, lo que podrá ser un punto de partida para otras investigaciones.

\section{Diseño metodológico}

Se diseñó un estudio con características no experimentales, transversal, descriptivo-correlacional, tomando como sujeto de estudio y fuente de información a los administradores o responsables del área de recursos humanos (o de aquellos que ejercieran la función de administrar al personal) en las empresas de Aguascalientes. Se considera como objeto de estudio las competencias y rasgos personales del perfil del administrador de RH, así como las prácticas de ARH con base en la fase de evolución; asimismo, como unidades de análisis se consideran las empresas de Aguascalientes que cuentan con área de administración de RH (área o persona que ejerza dicha función y que tenga por lo menos un empleado).

Para identificar las competencias del administrador o gestor de RH se diseñó un cuestionario con base en la propuesta descrita en la tabla 2 de este documento. Por otra parte, con la finalidad de reconocer y describir las prácticas de administra- 
El administrador de recursos humanos como gestor del talento humano...

ción de RH, se diseñó una entrevista semiestructurada con formato de matriz de seis columnas por fases de evolución de la gestión de RH: administrativa, de gestión, desarrollo, estratégica, por competencias y gestión del conocimiento; y en 28 renglones, las prácticas de administración de recursos humanos que incluyen funciones y actividades que van de lo más simple, en la fase administrativa, a lo más complejo en la fase de gestión del conocimiento, obteniendo así un instrumento de nueve páginas. En la tabla 4 se detalla su operacionalización y en la tabla 5 se presenta un ejemplo del diseño del instrumento.

\subsection{Población y cobertura de la muestra}

El estudio se llevó a cabo en empresas industriales, comerciales y de servicios de Aguascalientes, tomando en cuenta micro, pequeñas, medianas y grandes empresas. La población se identificó con fundamento en la clasificación del D.O.F. por acuerdo de la Secretaría de Comercio y Fomento Industrial publicado el 30 de marzo de 1999.

Con base en el Censo económico 1999, realizado por el Instituto Nacional de Estadística, Geografía e Informática (INEGI, 2001), en el estado de Aguascalientes predomina la microempresa en un $94.54 \%$, el $3.91 \%$ es pequeña, el $1.22 \%$ es mediana y el $0.32 \%$ es gran empresa, de las cuales el $12.34 \%$ pertenece al sector industrial, el $50.85 \%$ al comercial y el $36.81 \%$ al de servicios.

El muestreo fue no probabilístico (también llamado determinístico), por ello se seleccionó la muestra por conveniencia del investigador, dirigida por criterios de algunos especialistas (Lockwood, 1966 en Hernández, Fernández y Baptista, 2003:330). Se tomaron en cuenta empresas que tuvieran por lo menos un empleado y que realizaran funciones de administración de recursos humanos, así como se consideró el lugar geográfico donde hubiera un mayor número de empresas. En este tipo de muestreo no hay una fórmula previamente estructurada para determinar el tamaño de la muestra, por lo que se llevó a cabo un análisis de la literatura de estudios empíricos relacionados con el tema con la finalidad de conocer el tamaño de la muestra utilizada, el tipo de análisis empleado, la fuente de información de los datos; se obtuvo un promedio de 159 unidades de análisis. Sin embargo, según el autor Hair et al. (1999) recomiendan tamaños que vayan de 100 y 200 para realizar análisis multivariados. Para este estudio se obtuvo una muestra de 219 empresas de Aguascalientes: el 25.11\% fueron de manufactura, el 51.14\% 
comerciales, el $20.55 \%$ de servicios y $3.20 \%$ de otro tipo de empresas. De las cuales el $56.2 \%$ fueron microempresas, el $14.2 \%$ pequeñas, el $13.7 \%$ medianas y el $16.0 \%$ fueron grandes empresas. Se pudo observar que las empresas de Aguascalientes atienden mercados locales $(51.60 \%)$, regionales $(11.42 \%)$, nacionales $(19.63 \%)$, internacionales $(10.50 \%)$ y globales $(6.85 \%)$. Predomina el origen del capital nacional en $87.21 \%$, aunque también se refleja el origen de capital extranjero (5.48\%) y sólo el $7.31 \%$ de las empresas tienen origen de capital mixto (nacional y extranjero).

Entre las características demográficas de los 219 administradores o gestores de RH, que dieron respuesta al cuestionario y entrevista semiestructurada, predominan: ejecutivos del género femenino con $63.0 \%$ contra $37.0 \%$ del masculino. La edad oscila con el $44.3 \%$ entre 18 a 30 años y con $29.7 \%$, de 31 a 40 años; con nivel de licenciatura en un $49.8 \%$, pero de las carreras de licenciatura sólo el $22.8 \%$ con carreras de administración, el $23.3 \%$ con otros estudios profesionales y técnicos diferentes a administración, y el $33.3 \%$ ejecutivos sin carrera, ni estudios profesionales ni técnicos; con ocupación previa de empleado en un 34.3\% y una antigüedad de cinco años o menos en un $65.8 \%$ y $22.8 \%$ de seis a 10 años preponderantemente.

La cobertura del estudio se circunscribe al muestreo no probabilístico empleado, por conveniencia del investigador, que no permite la generalización de los datos y sus resultados circundan únicamente la muestra representada.

\subsection{Operacionalización y medición de las variables}

\section{a) Variable perfil del administrador}

Se definió la variable perfil del administrador como el conjunto o combinación de competencias o características generales, rasgos personales y demográficos que distinguen al administrador de RH para tener un desempeño exitoso y le faciliten la solución de situaciones y problemas del área que dirige, relacionadas con el personal. Las dimensiones que integran esta variable son: competencias cognitivas, competencias conductuales y competencias técnicas, rasgos personales y características demográficas; sin embargo, en este estudio sólo se analizan las competencias y rasgos del perfil del administrador de $\mathrm{RH}$, mismas que se detallan en la tabla 3. 
El administrador de recursos humanos como gestor del talento humano...

Tabla 3

Variable: perfil del administrador de RH y sus dimensiones con indicadores, preguntas, valores y tipos de variables

\begin{tabular}{|c|c|c|c|}
\hline $\begin{array}{c}\text { Dimensiones de la } \\
\text { variable } \\
\text { Medida }\end{array}$ & $\begin{array}{c}\text { Indicadores de las dimensiones de la } \\
\text { variable }\end{array}$ & $\begin{array}{l}\text { No. preguntas } \\
\text { y valores }\end{array}$ & Tipos de variables \\
\hline $\begin{array}{l}\text { Rasgos personales. } \\
\text { Conjunto de } \\
\text { características perso- } \\
\text { nales que disponen al } \\
\text { administrador de } \mathrm{RH} \\
\text { a comportarse de una } \\
\text { determinada manera, } \\
\text { enfocando su } \\
\text { comportamiento } \\
\text { hacia la toma de } \\
\text { decisiones. }\end{array}$ & $\begin{array}{l}\text { E1 indicador es la frecuencia como se } \\
\text { comporta, así, el responsable de recursos } \\
\text { humanos elige la que mejor lo describe. } \\
\text { Dimensiones: } \\
\text { 1.Flexibilidad, 2. Se adapta, 3. Toma } \\
\text { buenas decisiones, } 4 \text {. Es dinámico, 5. Es } \\
\text { visionario, } 6 \text {. Tiene autoconfianza, } 7 \text {. Es } \\
\text { competente, } 8 \text {. Toma en cuenta valores } \\
\text { humanos, } 9 \text {. Es paciente y } 10 \text {. Es preciso y } \\
\text { firme en sus decisiones. }\end{array}$ & $\begin{array}{c}10 \\
5=\text { Siempre } \\
4=\text { Mayoría de las } \\
\text { veces } \\
3=\text { Regularmente } \\
2=\begin{array}{c}\text { Muy pocas veces } \\
1=\text { Nunca }\end{array}\end{array}$ & $\begin{array}{c}10 \\
\text { Categóricas } \\
\begin{array}{c}\text { Nivel de medición } \\
\text { ordinal }\end{array}\end{array}$ \\
\hline $\begin{array}{l}\text { Competencias } \\
\text { cognitivas } \\
\text { Conjunto de conoci- } \\
\text { mientos, habilidades } \\
\text { y capacidades rela- } \\
\text { cionadas con la } \\
\text { actuación de éxito en } \\
\text { un puesto de trabajo, } \\
\text { a través de los } \\
\text { procesos internos de } \\
\text { raciocinio, jerárquica- } \\
\text { mente organizados, } \\
\text { proyectados por el } \\
\text { administrador de RH } \\
\text { al ejercer sus } \\
\text { funciones. }\end{array}$ & $\begin{array}{l}\text { 1. .Pensamiento analítico, 2.Capacidad de } \\
\text { aprender, 3. Pensamiento crítico, } 4 \text {. } \\
\text { Habilidades para solucionar problemas, } 5 \text {. } \\
\text { Habilidades directivas, } 6 \text {. Conocimiento } \\
\text { de cultura organizacional, } 7 \text {. Eficiente en } \\
\text { el uso de información y análisis de datos, } \\
\text { 8. Creador de entornos de sociabilidad, } 9 \text {. } \\
\text { Conocimiento de la estrategia del negocio } \\
\text { y } 10 \text {. Habilidades de organización de } \\
\text { eventos y procesos de intercambio de } \\
\text { conocimientos. }\end{array}$ & $\begin{array}{c}10 \\
5=\text { Siempre } \\
4=\text { Mayoría de las } \\
\text { veces } \\
3=\text { Regularmente } \\
2=\begin{array}{c}\text { Muy pocas veces } \\
1=\text { Nunca }\end{array}\end{array}$ & $\begin{array}{c}10 \\
\text { Categóricas } \\
\begin{array}{c}\text { Nivel de medición } \\
\text { ordinal }\end{array}\end{array}$ \\
\hline $\begin{array}{l}\text { Competencias } \\
\text { conductuales } \\
\text { Conjunto de cono- } \\
\text { cimientos, habilida- } \\
\text { des y capacidades } \\
\text { relacionadas con la } \\
\text { actuación de éxito en } \\
\text { un puesto de trabajo, } \\
\text { a través del } \\
\text { desempeño del actuar } \\
\text { cotidiano del } \\
\text { administrador de RH. }\end{array}$ & $\begin{array}{l}\text { 1. Con iniciativa, 2. Con orientación hacia } \\
\text { la satisfacción del cliente, } 3 \text {. Planeando } \\
\text { sus funciones a mediano y largo plazos, } 4 \text {. } \\
\text { Con buena comunicación hacia el } \\
\text { personal, 5. Con habilidades } \\
\text { interpersonales, } 6 \text {. Trabajo en equipo, } 7 \text {. } \\
\text { Generando un ambiente de entusiasmo y } \\
\text { compromiso de las personas y reconocido } \\
\text { como líder, 8. Guía de compañeros y } \\
\text { subordinados, 9. Motivando al personal, } \\
\text { 10. Delegando funciones, 11. Cooperando } \\
\text { con el personal, 12. Tolerante ante } \\
\text { situaciones críticas, 13. Recompensando el } \\
\text { buen desempeño y } 14 \text {. Con alto grado de } \\
\text { realización. }\end{array}$ & $\begin{array}{c}14 \\
5=\text { Siempre } \\
4=\text { Mayoría de las } \\
\text { veces } \\
3=\text { Regularmente } \\
2=\text { Muy pocas veces } \\
1=\text { Nunca }\end{array}$ & $\begin{array}{c}14 \\
\text { Categóricas } \\
\begin{array}{c}\text { Nivel de medición } \\
\text { ordinal }\end{array}\end{array}$ \\
\hline $\begin{array}{l}\text { Competencias } \\
\text { técnicas } \\
\text { Conjunto de conoci- } \\
\text { mientos, habilidades } \\
\text { y capacidades rela- } \\
\text { cionadas con la } \\
\text { actuación de éxito en } \\
\text { un puesto de trabajo, } \\
\text { relacionadas con la } \\
\text { función específica del } \\
\text { puesto que desem- } \\
\text { peña el administrador } \\
\text { de RH }\end{array}$ & $\begin{array}{l}\text { 1.Administrador y visión de cambio, } 2 \text {. } \\
\text { Con habilidades para los negocios, } 3 \text {. Con } \\
\text { conocimiento de leyes laborales, } 4 \text {. Con } \\
\text { conocimiento de novedades informáticas, } \\
\text { 5. Con conocimiento del inglés, } 6 \text {. Con } \\
\text { conocimiento de administración general, } \\
\text { 7. Con habilidades técnicas y estratégicas } \\
\text { de su área, } 8 \text {. Se mantiene actualizado, } 9 \text {. } \\
\text { Tiene habilidades para reaccionar y } \\
\text { adaptarse a los cambios del ambiente, } 10 \text {. } \\
\text { Mantiene un alto involucramiento de la } \\
\text { función de ARH a la estrategia del } \\
\text { negocio, y 11. Tiene conocimiento de } \\
\text { administración internacional y } \\
\text { conocimiento de varias culturas. }\end{array}$ & $\begin{array}{c}11 \\
5=\text { Siempre } \\
4=\text { Mayoría de las } \\
\text { veces } \\
3=\text { Regularmente } \\
2=\text { Muy pocas veces } \\
1=\text { Nunca }\end{array}$ & $\begin{array}{c}11 \\
\text { Categóricas } \\
\begin{array}{c}\text { Nivel de medición } \\
\text { ordinal }\end{array}\end{array}$ \\
\hline \multicolumn{2}{|c|}{ TOTAL DE PREGUNTAS DE ESTA VARIABLE } & 45 & 45 \\
\hline
\end{tabular}

Fuente: Aportación de la autora 


\section{b) Identificación de fase de gestión y tipo de gestor}

Para identificar la fase de evolución y la principal forma de administrar del gestor, se tomó como base la tabla 1 y se diseñó un instrumento tipo test de frases incompletas, donde se ofrece una frase y varios finales posibles, y el encuestado (administrador) ha de elegir el que más se acerque a su manera de pensar (Navarro Susana, 2004). En este instrumento el administrador tenía que asignar una calificación, donde el "1" es la frase que menos describe su forma de administrar y el "6" la frase que mejor lo describe. La escala definida para cada frase descrita fue de "1 a 6 " donde el número uno se refiere a la fase administrativa y el seis a la fase de gestión del conocimiento. Con este instrumento únicamente se identificó la concepción del hombre, la orientación del personal, la percepción del personal y la relación laboral predominante (véase tabla 1).

\section{c) Variable prácticas de administración o gestión de recursos humanos}

Se definieron como prácticas de la administración de recursos humanos a las funciones y prácticas que realizan los responsables o encargados de la gestión de recursos humanos, y que para este estudio se integraron en 28 , tomando en cuenta únicamente cuando el administrador o gestor de recursos humanos manifestó su aplicación.

Para medir las prácticas de la gestión o administración de recursos humanos se desarrolló el instrumento de entrevista-semiestructurada, quedando la operacionalización como se muestra en la tabla 4. 
El administrador de recursos humanos como gestor del talento humano...

Tabla 4

Variable: prácticas de ARH, preguntas, valores y tipos de variables

\begin{tabular}{|c|c|c|c|}
\hline $\begin{array}{l}\text { Dimensiones de la variable } \\
\text { Medida }\end{array}$ & $\begin{array}{c}\text { Indicadores de las } \\
\text { dimensiones de la } \\
\text { variable }\end{array}$ & $\begin{array}{l}\text { No. preguntas y } \\
\text { valores }\end{array}$ & $\begin{array}{c}\text { Tipos de } \\
\text { variables y } \\
\text { escala medición }\end{array}$ \\
\hline $\begin{array}{l}\text { Prácticas de la ARH } \\
\text { 1.Reclutamiento } \\
\text { 2.Selección } \\
\text { 3.Contratación y despido. } \\
\text { 4.Inducción o integración. } \\
\text { 5.Adiestramiento } \\
\text { 6.Capacitación y desarrollo. } \\
\text { 7.Formación de Personal. } \\
\text { 8.Planeación de vida y carrera } \\
\text { 9.Administración de sueldos y salarios. } \\
\text { 10.Criterios de promoción } \\
\text { 11.Diseño y proceso de trabajo (Análisis y } \\
\text { descripción de puestos) } \\
\text { 12.Relaciones laborales y negociaciones } \\
\text { colectivas } \\
\text { 13.Procedimiento de quejas } \\
\text { 14.Higiene y seguridad industrial } \\
\text { 15.Evaluación del desempeño } \\
\text { 16.Planeación de RH } \\
\text { 17.Planeación estratégica de RH } \\
\text { 18. Registros y controles administrativos. } \\
\text { 19.Registros y controles estratégicos } \\
\text { 20.Índices de rotación y ausentismo } \\
\text { 21.Gráficas y estadísticas } \\
\text { 22.Motivación y comunicación del personal } \\
\text { 23.Auditoría de RH } \\
\text { 24.Computadora como herramienta de control. } \\
\text { 25.Administración Internacional de RH } \\
\text { 26.Ética en el trabajo } \\
\text { 27.Responsabilidad social } \\
\text { 28.Programa de Calidad }\end{array}$ & $\begin{array}{l}\text { Para el Ejecutivo RH } \\
\text { Preguntas guía por ser } \\
\text { entrevista semiestructu- } \\
\text { rada. Y una matriz de } \\
\text { grados de sofisticación } \\
\text { de seis fases de } \\
\text { evolución de la gestión } \\
\text { de RH por } 28 \text { prácticas } \\
\text { de administración de } \\
\text { RH. }\end{array}$ & 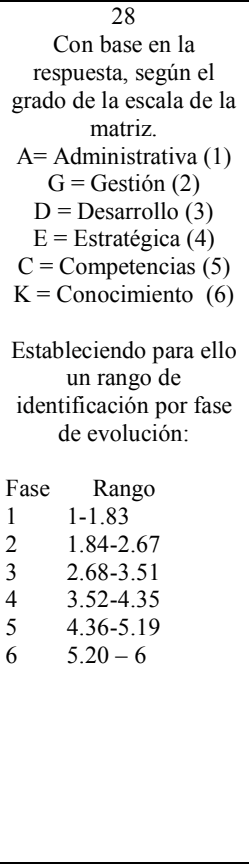 & $\begin{array}{c}28 \\
\text { Categóricas } \\
\text { ordinales }\end{array}$ \\
\hline $\begin{array}{l}\text { TOTAL DE PRÁCTICAS EN ESTA VARI } \\
\text { CUESTIONARIO }\end{array}$ & E DEL & 28 & 28 \\
\hline
\end{tabular}

Fuente: Aportación de la autora

Con la operacionalización de la tabla 4, el diseño de la "entrevista semiestructurada" fue con formato de matriz de seis columnas por veintiocho renglones, conteniendo como título de las columnas las seis fases de evolución: administrativa (A), gestión (G), desarrollo (D), estratégica (E), por competencias (C) y del conocimiento $(\mathrm{K})$ y como renglones, las 28 prácticas de administración o gestión de RH. Con la finalidad de identificar las fases de evolución con base en las prácticas y 
actividades que manifestaron los administradores o gestores de $\mathrm{RH}$, se definieron criterios de identificación por fase de evolución. Estos criterios fueron útiles para realizar la captura y el análisis de la entrevista y fueron los siguientes:

- La base de selección e identificación de la fase de evolución es ponderada, el valor de cada fase es acumulado al número de la elección, quedando como sigue:

$\begin{array}{llcc}\text { Fase } & \text { Denominación de la fase } & \text { Peso de la Fase } & \text { Valor acumulado } \\ 1 & \text { Administrativa (A) } & 1 & 1 \\ 2 & \text { Gestión (G) } & 2 & 3 \\ 3 & \text { Desarrollo (D) } & 3 & 6 \\ 4 & \text { Estratégica (E) } & 4 & 10 \\ 5 & \text { Por Competencias (C) } & 5 & 15 \\ 6 & \text { Del Conocimiento (K) } & 6 & 21\end{array}$

- Las prácticas por fase son acumuladas, no son excluyentes porque representan el grado de sofisticación que se va incrementando a medida que evoluciona la gestión de recursos humanos (véase tabla 1).

- Se toma en cuenta la práctica en cuanto a la fase que reúne mayor número de prácticas, tomando como principal indicador el enfoque y las actividades que realizan.

- En las prácticas en la que se haya señalado en la siguiente fase solamente un criterio y ése sea característico de la fase como: enfoque u orientación específica, se tomará en cuenta como predominio.

- El "no aplica" se considera en la fase 1 (administrativa) cuando así lo manifiesta el administrador o gestor de recursos humanos.

- El "en proceso" se considera en la fase 2 (gestión) cuando lo manifiesta el administrador o gestor de recursos humanos.

- Para las respuestas adicionales, no contempladas en la entrevista, se tomó el enfoque en que lo dijo el entrevistado y la fase en que lo explicó y se fue agregando.

- Si las prácticas señaladas en la siguiente fase son las mismas que en la anterior, se considera la anterior. Si señalan una, dos o más de la fase siguiente se toma la siguiente fase debido a que son acumuladas. 
El administrador de recursos humanos como gestor del talento humano...

- Si es una práctica única, se toma en cuenta la señalada cuidando que no se encuentre en una fase previa o posterior. De ser el caso, se considera donde la fase aparece en primera ocasión.

- Para análisis de datos se estableció el siguiente rango por fase:

Fase

Administrativa

Gestión

Desarrollo

Estratégica

Competencias

Conocimiento

\section{Rango}

$1-1.83$

$1.84-2.67$

$2.68-3.51$

$3.52-4.35$

$4.36-5.19$

5.20 a 6

Se utilizaron las siguientes fórmulas:

$$
R=U-L \quad R=6-1=5
$$

Donde: $R=$ Rango $\quad U=$ Medida mayor $\quad L=$ Medida menor o mínima. $\mathrm{w}=\frac{R}{c} \quad \mathrm{w}=\frac{5}{6} \quad=.83$ Amplitud de cada clase.

Donde: $w=$ amplitud de clase $R=$ Rango $\quad c=$ Número de clases.

A continuación se ejemplifica en la tabla 5 la práctica de reclutamiento del esquema de la matriz utilizada, se presenta únicamente como ejemplo en virtud de que la entrevista semiestructurada consta de nueve páginas. 
Tabla 5

Ejemplo de la práctica de reclutamiento del instrumento de entrevista semiestructurada en formato de matriz

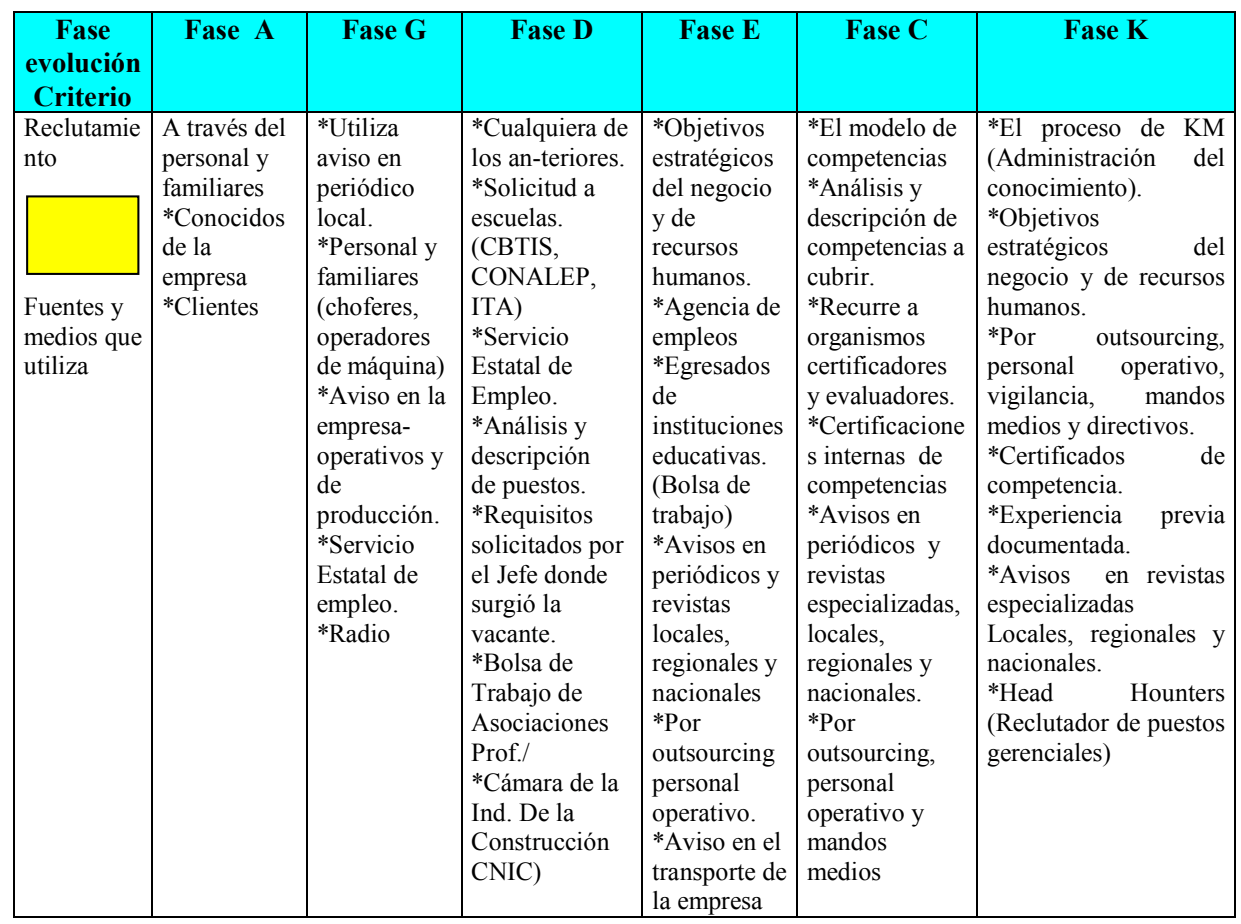

Nota: El instrumento consta de 28 prácticas de administración o gestión de recursos humanos que se definieron en la tabla 4 y que sigue el mismo esquema que el presentado en esta tabla. En el recuadro sombreado, se anota el nombre del área que realiza la función si es distinta al área de RH. Este ejemplo está adoptado al tamaño de la hoja vertical, pero el esquema original es en formato horizontal.

Fuente: Aportación de la autora

\subsection{Validez de los instrumentos de medición}

Por ser una propuesta teórica fundamentada en clasificaciones de autores de otras culturas, fue necesario realizar el procedimiento de validación del instrumento. Para calcular la validez del instrumento relacionado con las competencias y ras- 
El administrador de recursos humanos como gestor del talento humano...

gos del administrador de RH, se utilizó el análisis factorial exploratorio-que es útil para la búsqueda de una estructura entre una serie de variables (Hair et al., 1999) y es una "técnica de reducción de datos que sirve para encontrar grupos homogéneos de variables a partir de un conjunto numeroso" (Pardo Merino y Ruiz Díaz, 2002) - debido a que este análisis busca identificar que cada factor represente un valor teórico específico (Hintze, J. 2001), aplicando el método de rotación ortogonal varimax, que respeta la independencia entre factores de la solución inicial y minimiza el número de variables que tienen saturaciones altas en cada factor y simplifica la interpretación de los factores optimizando la solución por columna. (Pardo y Ruiz, 2002) y que redistribuye la varianza de los primeros factores a los últimos para lograr un patrón de factores más simple y teóricamente más significativo (Hair et al., 1999). Se utilizó en la selección de factores el "criterio a priori", que resulta de utilidad cuando se prueba una teoría o hipótesis acerca del número de factores para ser extraído así como el "criterio de porcentaje de la varianza", que se basa en obtener un porcentaje acumulado especificado de la varianza total extraída, donde los factores extraídos cuenten por lo menos con un $95 \%$ de la varianza. (Hair et al., 1999).

Se aplicó el software "NCSS 2001 and PASS" (Hintze, J. 2001), estableciendo el criterio de considerar sólo cargas superiores o iguales a 0.40 como significativas con base en las directrices para identificación de cargas (Hair et al., 1999:99); es necesario aclarar que se requiere un tamaño muestral necesario para la significación de 200, y en este caso, fue de 219. El análisis factorial se realizó con las competencias y rasgos personales propuestos en la tabla 2, y definidos en la tabla 3. Las construcciones teóricas que se midieron fueron: 1 Rasgos personales (Rasg), 2. Competencias cognitivas $(\mathrm{Cog}), 3$. Competencias conductuales (Cond) y 4. Competencias técnicas $(\mathrm{Tec})$, como a continuación se detallan en la tabla 6: 
Tabla 6

Construcciones teóricas sometidas a validación con análisis factorial, emanadas de la propuesta definida previamente en la tabla 1

\begin{tabular}{|c|c|c|c|}
\hline 1) Rasgos personales & $\begin{array}{l}\text { 2) Competencias } \\
\text { cognitivas }\end{array}$ & $\begin{array}{l}\text { 3) Competencias } \\
\text { conductuales }\end{array}$ & $\begin{array}{l}\text { 4) Competencias } \\
\text { técnicas }\end{array}$ \\
\hline $\begin{array}{l}\text { Rasg1-Flexibilidad en la } \\
\text { toma de decisiones } \\
\text { Rasg2-Se adapta a las } \\
\text { circunstancias } \\
\text { Rasg3-Toma buenas } \\
\text { decisiones } \\
\text { Rasg4-Dinámico cuando } \\
\text { toma decisiones } \\
\text { Rasg5-Visionario al } \\
\text { tomar una decisión } \\
\text { Rasg6-Tiene } \\
\text { autoconfianza } \\
\text { Rasg7-Competente } \\
\text { Rasg8-Valores humanos } \\
\text { Rasg9-Paciente } \\
\text { Rasg10-Preciso y firma en } \\
\text { sus decisiones }\end{array}$ & $\begin{array}{l}\text { Cog1-Pensamiento } \\
\text { analítico } \\
\text { Cog2-Capacidad de } \\
\text { aprender } \\
\text { Cog3-Pensamiento crítico } \\
\text { Cog4-Habilidades para } \\
\text { solucionar problemas } \\
\text { Cog5-Habilidades } \\
\text { directivas } \\
\text { Cog6-Conocimiento de la } \\
\text { cultura organizacional } \\
\text { Cog7-Uso de información } \\
\text { y análisis de datos } \\
\text { Cog8-Creador de } \\
\text { entornos de sociabilidad } \\
\text { Cog9-Conocimiento de la } \\
\text { estrategia del negocio } \\
\text { Cog10-Habilidades de } \\
\text { organización de eventos y } \\
\text { procesos de intercambio } \\
\text { de conocimientos. }\end{array}$ & $\begin{array}{l}\text { Cond1-Iniciativa } \\
\text { Cond2-Orientación hacia } \\
\text { la satisfacción del cliente } \\
\text { Cond3-Planeación de } \\
\text { funciones a mediano y } \\
\text { largo plazos } \\
\text { Cond4-Comunicación } \\
\text { hacia el personal } \\
\text { Cond5-Habilidades } \\
\text { interpersonales } \\
\text { Cond6-Trabajo en equipo } \\
\text { Cond7-Ambiente de } \\
\text { entusiasmo y compromiso } \\
\text { Cond8-Líder - guía de } \\
\text { compañeros y } \\
\text { subordinados } \\
\text { Cond9-Motivación al } \\
\text { personal } \\
\text { Cond10-Delegando } \\
\text { Cond11-Cooperando } \\
\text { Cond12-Tolerante } \\
\text { Cond13-Recompensando } \\
\text { el desempeño } \\
\text { Cond14-Alto grado de } \\
\text { realización. }\end{array}$ & $\begin{array}{l}\text { Tec1-Administrador y } \\
\text { visión de cambio } \\
\text { Tec2-Habilidades para los } \\
\text { negocios } \\
\text { Tec3-Conocimiento de } \\
\text { leyes laborales } \\
\text { Tec4-Conocimiento de } \\
\text { informática } \\
\text { Tec5-Conocimiento del } \\
\text { inglés } \\
\text { Tec6-Conocimiento de } \\
\text { administración general } \\
\text { Tec7-Habilidades técnicas } \\
\text { y estratégicas de su área } \\
\text { Tec8-Actualización } \\
\text { Tec9-Habilidades para } \\
\text { reaccionar y adaptarse a } \\
\text { los cambios } \\
\text { Tec10-Involucramiento de } \\
\text { la función de ARH a la } \\
\text { estrategia del negocio } \\
\text { Tec11-Conocimiento de } \\
\text { administración } \\
\text { internacional y varias } \\
\text { culturas }\end{array}$ \\
\hline
\end{tabular}

Fuente: Aportación de la autora

Después de realizar el análisis factorial con rotación varimax de las 45 dimensiones de las cuatro construcciones teóricas de las variables, se obtuvo la estructura de cuatro factores que se presenta en la tabla 7 , que integra las variables que tuvieron cargas $\geq 0.40$ y que además sus autovalores fueron mayores que " 1 " y la varianza explicada fue del $98.82 \%$ de los datos. 
El administrador de recursos humanos como gestor del talento humano...

Tabla 7

Resultados finales de la estructura factorial encontrada después de la rotación varimax indicando las cargas por variable

\begin{tabular}{|c|c|c|c|c|c|c|c|}
\hline \multicolumn{2}{|c|}{$\begin{array}{c}\text { Factor } 1 \\
\text { Competencias } \\
\text { cognitivas }\end{array}$} & \multicolumn{2}{|c|}{$\begin{array}{c}\text { Factor } 2 \\
\text { Competencias } \\
\text { técnicas }\end{array}$} & \multicolumn{2}{|c|}{$\begin{array}{c}\text { Factor } 3 \\
\text { Competencias } \\
\text { conductuales }\end{array}$} & \multicolumn{2}{|c|}{$\begin{array}{c}\text { Factor } 4 \\
\text { Rasgos personales }\end{array}$} \\
\hline $\begin{array}{l}\text { Propuesta } \\
\text { (10) }\end{array}$ & $\begin{array}{c}\text { Escala } \\
\text { Final - } \\
\text { Factorial } \\
(10)\end{array}$ & $\begin{array}{l}\text { Propuesta } \\
\text { (11) }\end{array}$ & $\begin{array}{c}\text { Escala } \\
\text { Final- } \\
\text { Factorial } \\
(9)\end{array}$ & $\begin{array}{l}\text { Propuesta } \\
\text { (14) }\end{array}$ & $\begin{array}{c}\text { Escala } \\
\text { Final - } \\
\text { Factorial } \\
(9)\end{array}$ & $\begin{array}{l}\text { Propuesta } \\
\text { (10) }\end{array}$ & $\begin{array}{c}\text { Escala } \\
\text { Final - } \\
\text { Factorial } \\
\text { (5) }\end{array}$ \\
\hline $\begin{array}{l}\text { Cog1 } \\
\text { Cog2 } \\
\text { Cog3 } \\
\text { Cog4 } \\
\text { Cog5 } \\
\operatorname{Cog} 6 \\
\operatorname{Cog} 7 \\
\operatorname{Cog} 8 \\
\operatorname{Cog} 9 \\
\operatorname{Cog} 10\end{array}$ & $\begin{array}{l}\text { Cog1 } \\
-0.506809 \\
\text { Cog3 } \\
-0.507732 \\
\text { Cog4 } \\
-0.559466 \\
\text { Cog5 } \\
-\mathbf{0 . 6 4 5 4 6 1} \\
\text { Cog6 } \\
-0.677974 \\
\text { Cog7 } \\
-\mathbf{0 . 5 2 5 2 9 8} \\
\text { Cog8 } \\
-\mathbf{0 . 5 8 1 6 0 0} \\
\text { Cog9 } \\
-0.442458 \\
\text { Cog10 } \\
-0.584583\end{array}$ & $\begin{array}{l}\text { Tec1 } \\
\text { Tec2 } \\
\text { Tec3 } \\
\text { Tec4 } \\
\text { Tec5 } \\
\text { Tec6 } \\
\text { Tec7 } \\
\text { Tec } 8 \\
\text { Tec } 9 \\
\text { Tec10 } \\
\text { Tec } 11\end{array}$ & $\begin{array}{l}\text { Tec3 } \\
0.640206 \\
\text { Tec4 } \\
0.741227 \\
\text { Tec5 } \\
0.685333 \\
\text { Tec6 } \\
0.760987 \\
\text { Tec7 } \\
0.763237 \\
\text { Tec8 } \\
0.773170 \\
\text { Tec9 } \\
0.641464 \\
\text { Tec10 } \\
0.647321 \\
\text { Tec11 } \\
0.587201\end{array}$ & $\begin{array}{l}\text { Cond1 } \\
\text { Cond2 } \\
\text { Cond3 } \\
\text { Cond4 } \\
\text { Cond5 } \\
\text { Cond6 } \\
\text { Cond7 } \\
\text { Cond8 } \\
\text { Cond9 } \\
\text { Cond10 } \\
\text { Cond11 } \\
\text { Cond12 } \\
\text { Cond13 } \\
\text { Cond14 }\end{array}$ & $\begin{array}{l}\text { Cond3 } \\
-0.516535 \\
\text { Cond4 } \\
-0.507409 \\
\text { Cond6 } \\
-0.612138 \\
\text { Cond7 } \\
-0.712207 \\
\text { Cond8 } \\
-\mathbf{0 . 6 1 5 0 4 7} \\
\text { Cond9 } \\
-0.633676 \\
\text { Cond10 } \\
-0.596987 \\
\text { Cond11 } \\
-0.690807 \\
\text { Cond12 } \\
-0.616391 \\
\text { Cond14 } \\
-0.526252\end{array}$ & $\begin{array}{l}\text { Rasg1 } \\
\text { Rasg2 } \\
\text { Rasg3 } \\
\text { Rasg4 } \\
\text { Rasg5 } \\
\text { Rasg6 } \\
\text { Rasg7 } \\
\text { Rasg8 } \\
\text { Rasg9 } \\
\text { Rasg10 }\end{array}$ & $\begin{array}{l}\text { Rasg6 } \\
-0.588111 \\
\text { Rasg7 } \\
-0635200 \\
\text { Rasg8 } \\
-0.602050 \\
\text { Rasg9 } \\
-\mathbf{- 0 . 6 0 3 3 9 2} \\
\text { Rasg10 } \\
\quad-0.666341\end{array}$ \\
\hline
\end{tabular}

Porcentajes de varianza explicada del análisis factorial

\begin{tabular}{|c|c|c|c|}
\hline $\begin{array}{c}\text { No. } \\
\text { Factores }\end{array}$ & Autovalores & $\begin{array}{c}\text { Porcentaje } \\
\text { individual }\end{array}$ & $\begin{array}{c}\text { Porcentaje } \\
\text { acumulado }\end{array}$ \\
\hline 1 & 3.773189 & 23.06 & 23.06 \\
\hline 2 & 5.150740 & 31.48 & 54.53 \\
\hline 3 & 4.623780 & 28.26 & 82.79 \\
\hline 4 & 2.622667 & 16.03 & 98.82 \\
\hline
\end{tabular}

Fuente: Aportación de la autora 


\section{Resultados}

En relación con el objetivo de identificar si el administrador de recursos humanos es un gestor del talento a través de sus principales formas de administrar y las prácticas que aplica y en respuesta a la pregunta ¿el administrador actual es un gestor del talento humano?, se realizó un análisis previo identificando por cada administrador cuál era la mayor ponderación (6), y asignando el número de fase a su respuesta: 1 a la fase administrativa, 2 a la de gestión, 3 a la de desarrollo, 4 a la estratégica, 5 a la gestión por competencias y 6 a la gestión del conocimiento, obteniendo posteriormente un análisis de frecuencias; los resultados obtenidos se presentan en la tabla 8 .

Tabla 8

Identificación de fase de gestión de las principales formas predominantes de administrar los recursos humanos

\begin{tabular}{|l|c|c|c|c|c|c|c|}
\hline $\begin{array}{c}\text { Formas de } \\
\text { administrar }\end{array}$ & $\begin{array}{c}\text { \% Fase } \\
\text { adminis } \\
\text { trativa }\end{array}$ & $\begin{array}{c}\text { \% Fase } \\
\text { de } \\
\text { gestión }\end{array}$ & $\begin{array}{c}\text { \% Fase } \\
\text { de } \\
\text { desarrollo }\end{array}$ & $\begin{array}{c}\text { \% Fase } \\
\text { estratégica }\end{array}$ & $\begin{array}{c}\text { \% Fase por } \\
\text { competencias }\end{array}$ & $\begin{array}{c}\text { \% Fase } \\
\text { gestión del } \\
\text { conocimiento }\end{array}$ & Moda \\
\hline $\begin{array}{l}\text { Concepciones } \\
\text { del hombre }\end{array}$ & 7.8 & 12.8 & 5.5 & 20.1 & 14.6 & 39.3 & 6 \\
\hline $\begin{array}{l}\text { Orientación } \\
\text { del personal }\end{array}$ & 6.4 & 3.2 & 42.9 & 24.7 & 16.9 & 5.9 & 3 \\
\hline $\begin{array}{l}\text { Percepción } \\
\text { del personal }\end{array}$ & 13.2 & 10.5 & 24.7 & 12.8 & 4.1 & 34.7 & 6 \\
\hline $\begin{array}{l}\text { Relaciones } \\
\text { laborales }\end{array}$ & 5.5 & 5.0 & 23.7 & 44.3 & 9.1 & 12.3 & 4 \\
\hline
\end{tabular}

Nota: análisis de frecuencias reflejado en porcentajes con indicación de la medida de tendencia central "moda". Los porcentajes sombreados son los predominantes.

Fuente: Aportación de la autora

Con los resultados que preceden en la tabla 8 , se puede argumentar con base en la información de la fase de evolución y el tipo de gestor definidas en la tabla 1, que el administrador actual de recursos humanos es gestor del talento en su forma de concebir al hombre, pues considera al personal como el talento clave para la empresa (39.3\%); en cuanto a la percepción de que el talento y conocimiento del personal integra el capital humano de la empresa (34.7\%); sin embargo, es administrador de recursos humanos porque orienta al personal hacia la eficiencia de la empresa (42.9\%); y es gestor estratégico de recursos humanos porque enfoca su relación laboral hacia el cumplimiento de los objetivos, con base en la estrategia del negocio. 
El administrador de recursos humanos como gestor del talento humano...

Cuando se relacionan los resultados en un análisis de tablas cruzadas y con prueba X2, en la tabla 11 donde se identifica la forma de administrar y el tipo de gestor con el porcentaje de la fase predominante; y las prácticas de administración y tipo de gestor, con el porcentaje por prácticas.

\section{Tabla 9}

\section{Análisis de tablas cruzadas con prueba $\mathrm{X}^{2}$ de la fase predominante, tipo de gestor y las prácticas que realiza de administración de recursos humanos}

\begin{tabular}{|c|c|c|c|c|c|c|c|c|c|c|c|c|}
\hline \multirow[t]{2}{*}{$\begin{array}{l}\text { Forma } \\
\text { adminis- } \\
\text { trar }\end{array}$} & \multirow[t]{2}{*}{$\begin{array}{l}\% \text { y Fase } \\
\text { predomi- } \\
\text { nante }\end{array}$} & \multirow[t]{2}{*}{$\begin{array}{l}\text { Tipo de } \\
\text { gestor }\end{array}$} & \multicolumn{6}{|c|}{$\begin{array}{c}\text { Prácticas de la administración } \\
\text { de } \mathrm{RH}, \% \text { dentro de la fase } \\
\text { predominante }\end{array}$} & \multirow[t]{2}{*}{$\begin{array}{l}\text { Tipo } \\
\text { de } \\
\text { gestor }\end{array}$} & \multirow[t]{2}{*}{$X^{2}$} & \multirow[t]{2}{*}{$\begin{array}{c}P \\
<05\end{array}$} & \multirow{2}{*}{$\begin{array}{c}\text { Ho } \\
\text { Inde- } \\
\text { pen- } \\
\text { dencia }\end{array}$} \\
\hline & & & 1 & 2 & 3 & 4 & 5 & 6 & & & & \\
\hline $\begin{array}{l}\text { Concepciones } \\
\text { del hombre }\end{array}$ & $\begin{array}{c}39.3 \% \\
\text { Gestión del } \\
\text { conocimiento }\end{array}$ & Talento & 38.4 & 11.6 & 25.6 & 15.1 & 9.3 & - & $\begin{array}{l}\text { Adminis- } \\
\text { trativo }\end{array}$ & 42.904 & .014 & Rechazo \\
\hline $\begin{array}{l}\text { Orientación } \\
\text { del personal }\end{array}$ & $\begin{array}{c}42.9 \% \\
\text { Gestión de } \\
\text { desarrollo }\end{array}$ & $\begin{array}{l}\text { De } \\
\text { Recursos } \\
\text { Humanos }\end{array}$ & 59.6 & 17.0 & 13.8 & 5.3 & 3.2 & 1.1 & $\begin{array}{l}\text { Adminis- } \\
\text { trativo }\end{array}$ & 71.976 & .000 & Rechazo \\
\hline $\begin{array}{l}\text { Percepción } \\
\text { del personal }\end{array}$ & $\begin{array}{c}34.7 \% \\
\text { Gestión del } \\
\text { conocimiento }\end{array}$ & Talento & 32.9 & 10.5 & 34.2 & 13.2 & 7.9 & 1.3 & $\begin{array}{l}\text { Recursos } \\
\text { Humanos }\end{array}$ & 46.814 & .005 & Rechazo \\
\hline $\begin{array}{l}\text { Relación } \\
\text { laboral }\end{array}$ & $\begin{array}{c}44.3 \% \\
\text { Gestión } \\
\text { estratégica }\end{array}$ & Estratégico & 63.9 & 13.4 & 13.4 & 6.2 & 2.1 & 1.0 & $\begin{array}{l}\text { Adminis- } \\
\text { trativo }\end{array}$ & 67.507 & .000 & Rechazo \\
\hline
\end{tabular}

Nota: Análisis de tablas cruzadas, con prueba $\mathrm{X}^{2}$ de independencia donde Ho: Independencia, en todos los casos el nivel de significación $p<0.05$, por lo que se rechaza la hipótesis nula de independencia y se concluye que las variables están relacionadas. Los valores indicados en las prácticas son: $1=$ Prácticas en fase administrativa, $2=$ Prácticas en la fase de gestión, 3 = Prácticas en la fase de desarrollo, $4=$ Prácticas en la fase estratégica, $5=$ Prácticas en la fase de gestión por competencias y $6=$ Prácticas en la fase de gestión del conocimiento. Los porcentajes de las prácticas de la administración indican el valor de cada fase únicamente relacionado con el porcentaje y fase predominante de la "forma de administrar"

Fuente: Aportación de la autora

Los resultados obtenidos en la tabla 9 permiten argumentar que aunque el administrador concibe al hombre y percibe al personal como el talento clave y que ese talento y conocimiento integra el capital humano de la empresa, cuando realiza las prácticas de administración predomina su rol de gestor administrativo, y sólo en la percepción del personal, como gestor de recursos humanos; sin embargo, en este último se detecta un porcentaje alto como gestor administrativo (32.9\%). Lo 
anterior se puede interpretar que aunque su pensamiento ha evolucionado a la gestión del conocimiento del talento humano en las prácticas de administración predomina su rol como gestor administrativo.

En cumplimiento a los objetivos de identificar y describir las competencias y rasgos personales del perfil del administrador de recursos humanos y dar respuesta a la pregunta ¿cuáles son las competencias y rasgos del administrador de $\mathrm{RH}$ que está dirigiendo las empresas?, se realizó un análisis de frecuencias obteniendo los siguientes resultados que se reflejan en la tabla 10 .

Tabla 10

Competencias y rasgos personales del administrador de RH

\begin{tabular}{|c|c|c|c|}
\hline Clave & $\begin{array}{l}\text { Rasgos personales y competencias del perfil del administrador de } \\
\text { recursos humanos }\end{array}$ & Moda & $\begin{array}{c}\text { Porcentaje } \\
\text { predominante }\end{array}$ \\
\hline \multicolumn{4}{|c|}{$\begin{array}{l}\text { Cuando el administrador de RH toma decisiones y requiere que se } \\
\text { implementen: }\end{array}$} \\
\hline Rasg6 & Tiene autoconfianza & 5 & 47.9 \\
\hline Rasg7 & Es competente & 4 & 54.3 \\
\hline Rasg8 & Toma en cuenta los valores humanos & 4 & 46.1 \\
\hline Rasg9 & Es paciente & 4 & 50.2 \\
\hline Rasg10 & Es preciso y firme en sus decisiones & 4 & 62.6 \\
\hline \multicolumn{4}{|c|}{ Cuando el administrador de RH ejerce sus funciones proyecta } \\
\hline $\operatorname{Cog} 1$ & Un pensamiento analítico & 4 & 53.4 \\
\hline $\operatorname{Cog} 3$ & Un pensamiento crítico en sus funciones & 4 & 55.3 \\
\hline $\operatorname{Cog} 4$ & Habilidades para solucionar problemas & 4 & 57.1 \\
\hline $\operatorname{Cog} 5$ & Sus habilidades directivas & 4 & 59.4 \\
\hline $\operatorname{Cog} 6$ & Conocimiento de la cultura organizacional & 4 & 51.1 \\
\hline $\operatorname{cog} 7$ & Eficiencia en el uso de información y análisis de datos & 4 & 48.9 \\
\hline $\operatorname{Cog} 8$ & Habilidades como creador de entornos de sociabilidad & 4 & 46.1 \\
\hline $\operatorname{Cog} 9$ & Conocimiento de la estrategia del negocio & 4 & 51.1 \\
\hline $\operatorname{Cog} 10$ & $\begin{array}{l}\text { Habilidades de organizador de eventos y procesos de intercambio de } \\
\text { conocimientos }\end{array}$ & 4 & 43.8 \\
\hline \multicolumn{4}{|c|}{ EI administrador de RH en su actuar cotidiano se desempeña } \\
\hline Cond3 & Planeando sus funciones, a mediano y largo plazos & 4 & 47.5 \\
\hline Cond 4 & Con buena comunicación hacia el personal & 4 & 47.9 \\
\hline Cond6 & Haciendo y trabajando en equipo & 4 & 38.8 \\
\hline Cond7 & $\begin{array}{l}\text { Generando un ambiente de entusiasmo y compromiso de las personas. } \\
\text { Reconocido como líder por el personal. }\end{array}$ & 4 & 50.7 \\
\hline Cond8 & Guiando a sus compañeros y subordinados & 4 & 55.7 \\
\hline Cond 9 & Motivando al personal & 4 & 48.9 \\
\hline Cond 10 & Delegando funciones & 4 & 50.7 \\
\hline Cond 11 & Cooperando con el personal & 4 & 52.1 \\
\hline Cond 12 & Tolerante a las situaciones críticas & 4 & 56.6 \\
\hline Cond 14 & Con alto grado de realización & 4 & 60.3 \\
\hline \multicolumn{4}{|c|}{ Cuando el administrador reflexiona sobre su manera de administrar los recursos humanos, opina } \\
\hline Tec3 & Tiene conocimiento de las leyes laborales & 4 & 39.3 \\
\hline Tec4 & Tiene conocimiento de las novedades informáticas & 4 & 42.0 \\
\hline Tec5 & Tiene conocimiento del idioma inglés & 4 & 27.9 \\
\hline Tec6 & Tiene conocimiento de administración general & 4 & 47.0 \\
\hline Tec7 & Tiene habilidades técnicas y estratégicas de su área & 4 & 46.1 \\
\hline Tec8 & Se mantiene actualizado & 4 & 39.7 \\
\hline Tec 9 & $\begin{array}{l}\text { Tiene habilidades para reaccionar y adaptarse a los cambios del } \\
\text { ambiente }\end{array}$ & 4 & 49.8 \\
\hline Tec 10 & $\begin{array}{l}\text { Mantiene un alto involucramiento de la función de recursos humanos a } \\
\text { la estrategia del negocio }\end{array}$ & 4 & 41.1 \\
\hline Tec11 & $\begin{array}{l}\text { Tiene conocimiento de administración internacional y conocimiento } \\
\text { de varias culturas. }\end{array}$ & 3 & 29.7 \\
\hline
\end{tabular}


El administrador de recursos humanos como gestor del talento humano...

Nota: Clave de los valores de resultados de la "moda" 5 = siempre, 4 = la mayoría de las veces, $3=$ regularmente. Solo se señalaron los resultados $\geq 50 \%$

Fuente: Aportación de la autora

En los resultados previos de la tabla 10 se señala que destacan las competencias cognitivas, conductuales y los rasgos personales de que es competente, además es paciente, firme y preciso en sus decisiones. Sin embargo se observa que las competencias técnicas, que son relacionadas con su función de administrar al personal, tienen menor porcentaje en que las aplica.

Para cumplir con el objetivo de conocer si existe relación entre las competencias cognitivas, conductuales, técnicas y los rasgos personales predominantes del gestor de recursos humanos con las prácticas que aplica de la administración de $\mathrm{RH}$, se dará respuesta a la pregunta ¿cuál es la relación de las competencias del perfil del administrador de RH con las prácticas de la administración de RH?, y probar las siguientes hipótesis estadísticas:

Ho: $p=0$ y Ha: $r>0$

Donde Ha es la hipótesis alternativa:

Ha. Existe una relación estadísticamente significativa entre las competencias cognitivas, conductuales, técnicas y los rasgos personales del perfil del administrador de recursos humanos (RH) con sus prácticas de administración de RH.

Planteando como Ho. No existe una relación estadísticamente significativa entre las competencias cognitivas, conductuales y los rasgos personales del perfil del administrador de recursos humanos $(R H)$ con sus prácticas de administración de $R H$.

Se realizó un análisis no paramétrico de correlación de Spearman con prueba de significación unilateral, donde la hipótesis nula es Ho: $\mathrm{p}=0$ y la alterna es Ha: $\mathrm{r}>$ 0 . (Gardner, Robert C, 2003), los resultados se detallan en la tabla 11 
Tabla 11

Resultados de la matriz de correlación entre las competencias y rasgos del perfil del administrador de $\mathbf{R H}$ y las 28 prácticas de administración de $\mathrm{RH}$

\begin{tabular}{|c|c|c|c|c|c|c|}
\hline $\begin{array}{c}\text { Clave } \\
\text { variable }\end{array}$ & Nombre de la variable & $\mathbf{N}$ & $\begin{array}{c}\text { Rasgos } \\
\text { Rho } \\
\text { Significación }\end{array}$ & \begin{tabular}{|c|} 
Cognitivas \\
Rho \\
Significación
\end{tabular} & $\begin{array}{c}\text { Conductuales } \\
\text { Rho } \\
\text { Significación }\end{array}$ & $\begin{array}{c}\text { Técnicas } \\
\text { Rho } \\
\text { Significación }\end{array}$ \\
\hline Practil & Reclutamiento & 219 & - & $\begin{array}{c}.234^{* * *} \\
.000\end{array}$ & $\begin{array}{c}.207^{* * *} \\
.001\end{array}$ & $\begin{array}{c}.370^{* * *} \\
.000\end{array}$ \\
\hline Practi2 & Selección & 219 & - & $\begin{array}{c}.209 * * \\
.001\end{array}$ & $\begin{array}{c}. .238 * * \\
.000\end{array}$ & $\begin{array}{c}.373^{* *} \\
.000\end{array}$ \\
\hline Practi3 & Contratación y despido & 219 & - & $\begin{array}{c}.151^{*} \\
.013\end{array}$ & $\begin{array}{c}.239 * * \\
.000\end{array}$ & $\begin{array}{c}.349 * * \\
.000\end{array}$ \\
\hline Practi4 & Inducción o Integración & 219 & $\begin{array}{l}.130^{*} \\
.028\end{array}$ & $\begin{array}{c}.207^{* *} \\
.001\end{array}$ & $\begin{array}{c}319 * * \\
.000\end{array}$ & $\begin{array}{c}.409^{* *} \\
.000\end{array}$ \\
\hline Practi5 & Adiestramiento & 219 &.- & - & $\begin{array}{c}.188 * * \\
.003\end{array}$ & $\begin{array}{c}.318 * * \\
.000\end{array}$ \\
\hline Practi6 & Capacitación y desarrollo & 219 & - &.- & $\begin{array}{c}.195^{* * *} \\
.002\end{array}$ & $\begin{array}{c}.340^{* * *} \\
.000\end{array}$ \\
\hline Practi7 & Formación de personal & 219 & - & $\begin{array}{c}.166^{* * *} \\
.007\end{array}$ & $\begin{array}{c}.314 * * \\
.000\end{array}$ & $\begin{array}{c}.392 * * \\
.000\end{array}$ \\
\hline Practi8 & Planeación vida y carrera & 219 & - & $\begin{array}{c}212^{* * *} \\
.001\end{array}$ & $\begin{array}{l}.235^{* * *} \\
.000\end{array}$ & $\begin{array}{c}.258^{* *} \\
.000\end{array}$ \\
\hline Practi9 & Administración sueldos & 219 & - & $\begin{array}{c}.129^{*} \\
.028\end{array}$ & $\begin{array}{c}.221 * * \\
.000\end{array}$ & $\begin{array}{c}.384^{* *} \\
.000\end{array}$ \\
\hline Practi10 & Criterios de promoción & 219 & $\begin{array}{l}.190^{* * *} \\
.002\end{array}$ & $\begin{array}{c}.226 * * \\
.000\end{array}$ & $\begin{array}{c}.234 * * \\
.000\end{array}$ & $\begin{array}{c}.334^{* *} \\
.000\end{array}$ \\
\hline Practil1 & Diseño y proceso de trabajo & 219 & $\begin{array}{l}.151^{*} \\
.013\end{array}$ & $\begin{array}{c}.232 * * \\
.000\end{array}$ & $\begin{array}{c}.264 * * * \\
.000\end{array}$ & $\begin{array}{c}.413^{* *} \\
.000\end{array}$ \\
\hline Practi12 & Relaciones laborales y $\mathrm{n}$ & 219 & - & - & $\begin{array}{c}.239 * * \\
.000\end{array}$ & $\begin{array}{c}.303^{* *} \\
.000\end{array}$ \\
\hline Practi13 & Procedimiento de quejas & 219 & - & $\begin{array}{c}.168^{* * *} \\
.006\end{array}$ & $\begin{array}{c}.265^{* * *} \\
.000\end{array}$ & $\begin{array}{c}.320^{* * *} \\
.000\end{array}$ \\
\hline Practi14 & Higiene y seguridad & 219 & $\begin{array}{l}.121 * \\
.037\end{array}$ & $\begin{array}{l}.121^{*} \\
.037\end{array}$ & $\begin{array}{c}.205^{* * *} \\
.001\end{array}$ & $\begin{array}{c}.318^{* *} \\
.000\end{array}$ \\
\hline Practi15 & Evaluación del desempeño & 219 & $\begin{array}{l}.119 * \\
.040\end{array}$ & $\begin{array}{c}.166^{* * *} \\
.007\end{array}$ & $\begin{array}{c}.247^{* * *} \\
.000\end{array}$ & $\begin{array}{c}.344^{* * *} \\
.000\end{array}$ \\
\hline Practi16 & Planeación de RH & 219 & - & $\begin{array}{c}.175^{* * *} \\
.000\end{array}$ & $\begin{array}{c}.196 * * * \\
.000\end{array}$ & $\begin{array}{c}.311^{* *} \\
.000\end{array}$ \\
\hline Practi17 & Planeación estratégica RH & 219 & - & $\begin{array}{c}.160 * * \\
.009\end{array}$ & $\begin{array}{c}.161 * * \\
.009\end{array}$ & $\begin{array}{c}.225^{* *} \\
.000\end{array}$ \\
\hline Practi18 & Registros y controles ad & 219 & $\begin{array}{c}.159^{* * *} \\
.009\end{array}$ & $\begin{array}{c}.219^{* * *} \\
.001\end{array}$ & $\begin{array}{c}.267 * * \\
.000\end{array}$ & $\begin{array}{c}.422 * * \\
.000\end{array}$ \\
\hline Practi19 & Controles estratégicos & 219 & $\begin{array}{l}.148^{*} \\
.014\end{array}$ & $\begin{array}{c}186^{* * *} \\
.003\end{array}$ & $\begin{array}{l}.202 * * * \\
.001\end{array}$ & $\begin{array}{c}.310^{* * *} \\
.000\end{array}$ \\
\hline Practi20 & Índices de rotación & 219 & - & $\begin{array}{c}.186^{* *} \\
.003\end{array}$ & $\begin{array}{c}.202 * * \\
.001\end{array}$ & $\begin{array}{c}.249^{* *} \\
.000\end{array}$ \\
\hline Practi21 & Gráficas y estadísticas & 219 & $\begin{array}{l}.150^{*} \\
.013\end{array}$ & $\begin{array}{c}.196^{* * *} \\
.002\end{array}$ & $\begin{array}{c}.246^{* * *} \\
.000\end{array}$ & $\begin{array}{c}.374 * * \\
.000\end{array}$ \\
\hline Practi22 & Motivación y comunicación & 219 & - & - & $\begin{array}{c}.249 * * \\
.000\end{array}$ & $\begin{array}{c}.279 * * \\
.000\end{array}$ \\
\hline Practi23 & Auditoría RH & 219 & - & - & - & $\begin{array}{c}.220 * * \\
.001\end{array}$ \\
\hline Practi24 & Computadora como herra & 219 & - & - & $\begin{array}{c}.214^{* * *} \\
.001\end{array}$ & $\begin{array}{c}.354^{* *} \\
.000\end{array}$ \\
\hline Practi25 & Administración Interna & 219 & - & $\begin{array}{c}.203 * * * \\
.001 \\
\end{array}$ & - & $\begin{array}{c}.275^{* *} \\
.000\end{array}$ \\
\hline Practi26 & Ética & 219 & - & - & $\begin{array}{c}.252 * * \\
.003\end{array}$ & $\begin{array}{l}.227^{* * *} \\
.000\end{array}$ \\
\hline Practi27 & Responsabilidad social & 219 & & & $\begin{array}{c}.188 * * \\
.003\end{array}$ & $\begin{array}{c}.245 * * \\
.000\end{array}$ \\
\hline Practi28 & Programa de calidad & 219 & $\begin{array}{c}.189 * * \\
.002\end{array}$ & $\begin{array}{c}.146 * * \\
.015\end{array}$ & $\begin{array}{l}.150^{*} \\
.013\end{array}$ & $\begin{array}{c}.238^{* * *} \\
.000\end{array}$ \\
\hline
\end{tabular}

Nota: Muestra de 219 administradores de RHCorrelación bivariada no paramétrica con coeficiente de correlación Rho de Spearman**Correlación significativa $<0.01$ (unilateral) *Correlación significativa $<0.05$ (unilateral)

Fuente: Aportación de la autora 
El administrador de recursos humanos como gestor del talento humano...

Con base en los resultados obtenidos en la tabla 11, se argumenta que como la hipótesis plantea la existencia de una "relación estadísticamente significativa" y ésta relación toma valores de -1 y 1 , donde un valor 0 indica relación lineal nula, y el valor 1 indica relación lineal perfecta positiva y el - 1, refleja relación lineal perfecta negativa (Pardo y Ruiz, 2002), se demuestra la existencia de la relación estadísticamente significativa entre los rasgos personales, las competencias cognitivas, conductuales y técnicas del perfil del administrador de $\mathrm{RH}$ con las prácticas de administración de $\mathrm{RH}$, pero sólo en las prácticas detalladas en la misma tabla 11. Estos datos pueden interpretarse que a mayor aplicación de prácticas mayores competencias técnicas, conductuales, cognitivas y rasgos del administrador de RH.

Para conocer cuáles son las competencias específicas y los rasgos personales que se relacionan con las prácticas de administración de $\mathrm{RH}$, se realizó otro análisis de correlación, aplicando análisis no paramétrico, de correlación de Spearman, con prueba de significación unilateral, donde la hipótesis nula es Ho: $\mathrm{p}=0$ y la alterna es Ha: $r>0$. (Gardner, Robert C, 2003), obteniendo los resultados que se señalan en la tabla 12. 
Tabla 12

Relación de rasgos y competencias del ejecutivo de RH con las prácticas de administración de RH

\begin{tabular}{|c|c|c|c|}
\hline \multirow{2}{*}{\multicolumn{2}{|c|}{ Rasgos y competencias del ejecutivo de RH }} & \multicolumn{2}{|c|}{ Prácticas de ARH } \\
\hline & & \multirow{2}{*}{$\begin{array}{c}\begin{array}{c}\text { Coeficiente } \\
\text { rho } \\
\text { Spearman }\end{array} \\
.138^{*}\end{array}$} & \multirow{2}{*}{$\begin{array}{c}\text { Nivel } \\
\boldsymbol{P} \\
.021\end{array}$} \\
\hline Rasg6 & Tiene autoconfianza & & \\
\hline Rasg8 & Toma en cuenta los valores humanos & $.419 * *$ & .000 \\
\hline $\operatorname{Cog} 1$ & Un pensamiento analítico & $.328^{* *}$ & .000 \\
\hline $\operatorname{Cog} 6$ & Conocimiento de la cultura organizacional & $.285 * *$ & .000 \\
\hline $\operatorname{Cog} 7$ & Es eficiente en el uso de información y análisis de datos & $.277^{* *}$ & .000 \\
\hline $\operatorname{Cog} 8$ & Habilidades como creador de entornos de sociabilidad & $.165 *$ & .014 \\
\hline $\operatorname{Cog} 10$ & $\begin{array}{l}\text { Habilidades como organizador de eventos y procesos } \\
\text { de intercambio de conocimientos }\end{array}$ & $.208 * *$ & .001 \\
\hline Cond4 & Con buena comunicación hacia el personal & $.159 *$ & .009 \\
\hline Cond6 & Haciendo y trabajando en equipo & $.319^{* *}$ & .000 \\
\hline Cond7 & $\begin{array}{l}\text { Generando un ambiente de entusiasmo y compromiso } \\
\text { de las personas, reconocido como líder del personal }\end{array}$ & $.151^{*}$ & .013 \\
\hline Cond 8 & Guiando a sus compañeros y subordinados & $.184 * *$ & .003 \\
\hline Cond9 & Motivando al personal & $.245^{* *}$ & .000 \\
\hline Cond11 & Cooperando con el personal & $.299^{* *}$ & .000 \\
\hline Cond 12 & Tolerante ante situaciones críticas & $.143 *$ & .017 \\
\hline Cond14 & Con alto grado de realización & $.163 *$ & .008 \\
\hline Tec3 & Tiene conocimiento de leyes laborales & $.347^{* *}$ & .000 \\
\hline Tec4 & Tiene conocimiento de novedades informáticas & $.322 * *$ & .000 \\
\hline Tec5 & Tiene conocimiento del inglés & $.232 * *$ & .001 \\
\hline Tec6 & Tiene conocimiento de administración general & $.367 * *$ & .000 \\
\hline Tec7 & Tiene habilidades técnicas y estratégicas de su área & $.427 * *$ & .000 \\
\hline Tec 8 & Se mantiene actualizado & $.398 * *$ & .000 \\
\hline Tec9 & $\begin{array}{l}\text { Tiene habilidades para reaccionar y adaptarse al } \\
\text { entorno }\end{array}$ & $.450 * *$ & .000 \\
\hline Tec10 & $\begin{array}{l}\text { Mantiene un alto involucramiento de la función de RH } \\
\text { a la estrategia del negocio. }\end{array}$ & $.397 * *$ & .000 \\
\hline Tec11 & $\begin{array}{l}\text { Tiene conocimiento de administración internacional y } \\
\text { conocimiento de varias culturas }\end{array}$ & $.205^{* *}$ & .001 \\
\hline
\end{tabular}

Nota: Muestra de 219 administradores de RH

Correlación bivariada no paramétrica con coeficiente de correlación Rho de Spearman

**Correlación significativa $<0.01$ (unilateral) $\quad *$ Correlación significativa $<0.05$ (unilateral)

Fuente: Aportación de la autora 
El administrador de recursos humanos como gestor del talento humano...

De acuerdo con los resultados de la tabla 12 se argumenta que el rasgo personal más significativo es que el administrador toma en cuenta los valores humanos, la principal competencia cognitiva es su pensamiento analítico; en cuanto a la competencia conductual es el desarrollo de su trabajo en equipo y la principal competencia técnica es que posee habilidades para reaccionar y adaptarse al entorno. Además se puede apreciar en relación con la frecuencia que manifiesta al aplicar sus rasgos y competencias, que las competencias técnicas que aplica con menor frecuencia son las que tienen mayor coeficiente de correlación con la aplicación de las prácticas de administración de recursos humanos; de allí la importancia de que el administrador de RH valore sus competencias y rasgos personales y conozca la influencia que tiene en la aplicación de las prácticas de las empresas; sin embargo, dependerá de la preparación y actualización del administrador y de las competencias que siga adquiriendo para mejorar el desempeño de sus funciones.

Con la finalidad de dar respuesta a las preguntas: ¿el administrador de RH está realizando prácticas de administración o gestión del conocimiento?, ¿está realizando prácticas en otras fases de evolución?, se generó un análisis de frecuencias con los resultados que se muestran en la tabla 13.

Tabla 13

Resultados de análisis de frecuencias de las formas y prácticas de administración de recursos humanos

\begin{tabular}{|l|c|c|c|}
\hline \multicolumn{1}{|c|}{ Fase de evolución } & $\begin{array}{c}\text { Porcentaje de } \\
\text { empresas por formas } \\
\text { de administrar } \\
\text { (integra las } \\
\text { descritas en la tabla } \\
\mathbf{1 1 )}\end{array}$ & $\begin{array}{c}\text { Porcentaje de } \\
\text { empresas por } \\
\text { prácticas en cada } \\
\text { fase }\end{array}$ & $\begin{array}{c}\text { Porcentaje promedio } \\
\text { de empresas con base a } \\
\text { la conjunción de } \\
\text { formas y prácticas de } \\
\text { ARH }\end{array}$ \\
\hline Administrativa & 1.4 & 43.8 & 22.6 \\
\hline Gestión & 31.5 & 16.4 & 23.9 \\
\hline Desarrollo & 32.4 & 22.4 & 27.4 \\
\hline Estratégica & 26.0 & 11.4 & 18.7 \\
\hline Por competencias & 7.8 & 5.5 & 6.7 \\
\hline $\begin{array}{l}\text { Gestión del } \\
\text { conocimiento }\end{array}$ & 0.91 & 0.5 & 0.7 \\
\hline Total & $100 \%$ & $100 \%$ & $100 \%$ \\
\hline
\end{tabular}

Fuente: aportación de la autora 
Con la información de la tabla 13 se observa que tanto en las formas de administración de recursos humanos como en las prácticas de ARH se identifican empresas en cada una de las seis fases de evolución de la gestión de RH; además, al revisar la información por separado se detecta un ligero predominio dentro de la fase de desarrollo con un $32.4 \%$, siguiendo en importancia las de gestión con un $31.5 \%$; mientras que en las prácticas predomina la administrativa (43.8\%); en la conjunción de ambas se observa un ligero predominio en la fase de desarrollo (27.4\%). De igual forma, se identifica que tanto en sus formas de administrar como en sus prácticas de gestión del conocimiento del talento humano resulta incipiente.

\section{Discusión}

Con base en los resultados obtenidos se puede argumentar que de acuerdo con Lugo (1999) los administradores de RH en Aguascalientes integran algunas competencias como conocimiento de la estrategia del negocio, es cooperador con el personal, así como posee habilidades para reaccionar y adaptarse a los cambios, lo que generaría la integración del nuevo perfil del administrador. De igual manera se coincide con Lugo (1999) en las competencias: haciendo y trabajando en equipo, conocimiento de administración general y habilidades técnicas y estratégicas de su área, además que los administradores de RH de Aguascalientes tienen la competencia conductual de ejercer una buena comunicación hacia el personal y una competencia técnica de que tienen conocimiento de administración internacional y conocimiento de varias culturas; no obstante, esta última fue de menor porcentaje y menor frecuencia en su aplicación.

\section{Conclusiones}

Se detecta la existencia de administradores que han evolucionado en su forma de pensar; se identifican como gestores del conocimiento del talento humano, pues reconocen al personal de la empresa como el talento clave; además, su conocimiento y talento integran el capital humano de la empresa; sin embargo en estos gestores, que tienen esa concepción y percepción del personal cuando aplican las prácticas, predominan los gestores administrativos, siguiendo en importancia la gestión de recursos humanos. Se requiere que los actuales administradores en las empresas de Aguascalientes mejoren sus prácticas de administración de recursos humanos para evolucionar al mismo ritmo que el ambiente en el que se desenvuelven. 
El administrador de recursos humanos como gestor del talento humano...

Se concluye que las competencias técnicas y las conductuales son las que en este estudio tienen una mayor contribución e impactan en la relación con las prácticas de administración de RH. Las competencias técnicas son que tienen conocimiento de las leyes laborales, tienen conocimiento de novedades informáticas, conocimiento de inglés, conocimiento de administración general, habilidades técnicas y estratégicas de su área, se mantienen actualizados, tienen habilidades para reaccionar y adaptarse al entorno, mantienen un alto involucramiento de la función de RH a la estrategia del negocio y tienen conocimiento de la administración internacional y conocimiento de varias culturas, aunque son las competencias que realiza con menor frecuencia. Por ello, se concluye que el administrador de $\mathrm{RH}$ requiere mejorar sus competencias técnicas para a su vez incrementar el grado de sofisticación en el ejercicio de las prácticas de administración de RH. En relación con las competencias conductuales, las que realiza con mayor frecuencia son: guían a sus compañeros y subordinados, cooperan con el personal, toleran situaciones críticas y con alto grado de realización. En cuanto a las que realiza con menos frecuencia y requiere mejorar son: buena comunicación con el personal, haciendo y trabajando en equipo, generar un ambiente de entusiasmo y compromiso de las personas, reconocer al líder y motivar al personal.

Por lo anterior, se puede afirmar que los administradores de $\mathrm{RH}$ de este estudio ejercen más funciones en las fases administrativa, de gestión, desarrollo y estratégicas; en consecuencia se les puede denominar gestores administrativos y de gestión, gestores de desarrollo y gestores estratégicos de recursos humanos. Es necesario que el lector administrador de RH (o que esté realizando estas funciones) analice las prácticas que está ejerciendo, analice las características de cada fase de evolución, analice la orientación que tiene en la empresa e identifique los rasgos y competencias que ejerce y que pueden estar contribuyendo o limitando su gestión.

En la medida en que el actual administrador de RH incremente sus competencias técnicas, cognitivas, conductuales y sus rasgos personales, realizará prácticas más sofisticadas y orientadas hacia la estrategia del negocio, así como logrará una identificación, descripción, desarrollo y certificación de competencias individuales para impulsar un nivel de excelencia hacia los resultados y hacia la orientación rumbo al aprendizaje, retención y motivación del conocimiento de los trabajadores, además de la generación del conocimiento, ligándolo a los objetivos del negocio; asimismo, se podrá incrementar el número de empresas en las fases de gestión estratégica, gestión por competencias y gestión del conocimiento; además, las 
denominaciones de la organización del área irán cambiando y, como consecuencia de ello, cambiará la denominación de administrador de recursos humanos hasta llegar a la de gestor del conocimiento o del talento humano.

\section{Referencias}

ADLER, Nancy J. \& Susan Bartholomew (1992), "Managing globally competent people", Academy of Management Executive, Vol. 6, i3, p. 52, 14 p. 1 Chart. Retrieved Aug 1992, en EBSCOhost database (Business Source Elite) en World Wide Web: http://search.epnet.com

ALLES, Martha Alicia (2000), Dirección estratégica de recursos humanos: gestión por competencias, Granica, Argentina.

CHIAVENATO, Idalberto (2002), Gestión del talento humano, Mc Graw-Hill Interamericana, Colombia.

GARCÍA PINEDA, Ancelmo y Andrés Hernández Sánchez (2000), "La gestión del conocimiento para fortalecer la competitividad de la empresa", IDC Información Dinámica de Consulta, sección Laboral, Servicio Quincenal de Consultoría Empresarial, 30 de abril de 2000, Año XIII, 2a . Época, No. 104, pp. 1132-1134.

GARDNER, Robert C. (2003), Estadística para psicología usando SPSS para WINDOWS, Pearson Educación, México.

HAIR, Joseph F. et al. (1999), Análisis multivariante, Prentice-Hall, España.

HERNÁNDEZ SAMPIERI, Roberto, C. Fernández Collado y Pilar Baptista Lucio (2003), Metodología de la investigación, 3ª ed., Mc Graw-Hill, México.

HINTZE, Jerry (2001) "NCSS and PASS Number Cruncher Statistical Systems", Kaysville, Utah, junio 2003, http://www.ncss.com (copyright (C) 2003). 
El administrador de recursos humanos como gestor del talento humano...

INSTITUTO NACIONAL DE ESTADÍSTICA GEOGRAFÍA E INFORMÁTICA, INEGI (2001), Micro, pequeña, mediana y gran empresa, estratificación de los establecimientos, Censo Económico 1999, INEGI, México, pp. 109,77 y 44.

LIQUIDANO RODRÍGUEZ, Ma. del Carmen (2005), El impacto del perfil del administrador de RH en la evolución de la gestión de recursos humanos y su relación en el desempeñoorganizacional en empresas de Aguascalientes (Proyecto de investigación para tesis doctoral. Resultados descriptivos preliminares), Academia de Ciencias Administrativas, A.C. (ACACIA) IX Congreso Anual, Mérida, Yucatán.

LÓPEZ, Carlos (2002) "Gestión del conocimiento: tarea de la gerencia de recursos humanos" en http://www.gestiopolis.com/canales/derrjj/artículos/36/ km.htm.

LOSEY, Michael (1998) HR comes of age. HR Magazine, Vol. 43, i.3, p.40, 14p. 1 chart, 13c, 13bw. en EBSCOhost database (Business Source Elite) en World Wide Web: http://search.epnet.com

LUGO CUELLAR, Luis Miguel (1999), Recursos humanos: evolución o revolución, Revista Competencia Laboral, Año 3, No. 11, julio-septiembre 1999.

NAVARRO, Susana (2004) Tests de personalidad, DIANA-LIBSA España.

PARDO MERINO, Antonio y Miguel Ángel Ruiz Díaz (2002), SPSS 11. Guía para el análisis de datos, McGraw-Hill Interamericana, España.

PLANE, Jean-Michel (2003), La gestion des Ressources Humaines, Económica, París, 112 pp.

SALLEH YAHYA \& Wee-Keat Goh (2002), "Managing human resources toward achieving knowledge Management", Journal of Knowledge Management, Vol.6, No. 5, pp.457-468. 
SIRIANNI, Carlo Alessandro (1992), "Human resource management in Italy", Employee Relations, Vol. 14, i5, p. 23 (Information service of the ProQuest Company).

VALLE CABRERA, Ramón (1995), La gestión estratégica de los recursos humanos, Addison-Wesley Iberoamericana, Estados Unidos, 1995, pp. 7-11.

WASILCZUK, Julita (2000), "Advantageous Competence of Owner / Managers to Grow the Firm in Poland: Empirical", Journal of Small Business Management, Vol. 38, i2, p88, 7 p., recuperado Abril 2000, en EBSCOhost database (Academic Search Elite) en World Wide Web:

http://search.epnet.com

WELBOURNE, Theresa M. \& Cyr, Linda A. (1999), "The human resource executive effect in initial public offering firms", Academy of Management Journal v. 42, i6, pp. 616-629 (Information service of the ProQuest Company).(\$) 